\title{
Anticancer activity of benzoxazole derivative (2015 onwards): a review
}

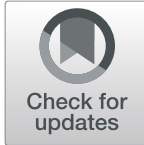

Tanay Ghoshal and Tarun M. Patel

\begin{abstract}
Background: According to the report published recently by the World Health Organization, the number of cancer cases in the world will increase to 22 million by 2030. So the anticancer drug research and development is taking place in the direction where the new entities are developed which are low in toxicity and are with improved activity. Benzoxazole and its derivative represent a very important class of heterocyclic compounds, which have a diverse therapeutic area. Recently, many active compounds synthesized are very effective; natural products isolated with benzoxazole moiety have also shown to be potent towards cancer.

Main text: In the last few years, many research groups have designed and developed many novel compounds with benzoxazole as their backbone and checked their anticancer activity. In the review article, the recent developments (mostly after 2015) made in the direction of design and synthesis of new scaffolds with very potent anticancer activity are briefly described. The effect of various heterocycles attached to the benzoxazole and their effect on the anticancer activity are thoroughly studied and recorded in the review.
\end{abstract}

Conclusion: These compiled data in the article will surely update the scientific community with the recent development in this area and will provide direction for further research in this area.

Keywords: Benzoxazole, Anticancer activity, Cytotoxicity, Cell lines, Antitumor activity, Anti-proliferative activity

\section{Background}

Cancer is a one of the major health problem for human beings with the leading mortality rate [1]. Natural, synthetic, or biological and chemical substances are the cancer-causing agents [2]. Many drugs are used to cure it, but they have their own toxic side effects [3]. Hence, there are lots of research carried out to synthesize new [4-6], effective, and affordable anticancer drugs with more selectivity, minimum dosage, and lesser side effects.

Drug discovery over the years have focussed more on the heterocyclic chemistry due to their huge success rate in forming active pharmaceutical intermediate. Among the heterocyclic compounds, benzoxazole is one of the most important heterocyclic compound which exhibit remarkable pharmacological activities [7-11]. There are

\footnotetext{
* Correspondence: drpatel16185@gmail.com

Shri M M Patel Institute of Science and Research, Kadi Sarva Vishwavidyalaya, Gandhinagar, Gujarat 382024, India
}

\section{Springer Open}

(c) The Author(s). 2020 Open Access This article is licensed under a Creative Commons Attribution 4.0 International License, which permits use, sharing, adaptation, distribution and reproduction in any medium or format, as long as you give appropriate credit to the original author(s) and the source, provide a link to the Creative Commons licence, and indicate if changes were made. The images or other third party material in this article are included in the article's Creative Commons licence, unless indicated otherwise in a credit line to the material. If material is not included in the article's Creative Commons licence and your intended use is not permitted by statutory regulation or exceeds the permitted use, you will need to obtain permission directly from the copyright holder. To view a copy of this licence, visit http://creativecommons.org/licenses/by/4.0/. many reportation of synthetic compounds and naturally occurring compounds with benzoxazole backbone showing a very active anti-cancer activity. Different research groups have done much progress in designing compounds with benzoxazole, synthesizing them, and collecting anticancer activity data of those against various human cancer cell lines. An attempt has been made to see how various heterocyclic moiety attached with benzoxazole have an effect on the anticancer activity of the various benzoxazole compounds synthesized by different groups. A compiled data of all these recent articles helps in providing a direction towards further research.

\section{Benzoxazole attached with various heterocyclic moiety and their anticancer activity Benzoxazole-piperazine moiety \\ Al-Harthy et al. [12] have designed few benzoxazole at- tached to piperazine derivatives and tested it over hu- man A-549 lung carcinoma cells. The initial results were}


not that satisfactory, and the results were low which was due to the low solubility of the aryl piperazine compounds, and these compounds precipitated in the cell culture media. The solubility of the compounds can be improved by using $\mathrm{N}$-methylpiperazine instead of aryl piperazine at position- 6 of the benzoxazole, and the methyl group at position-2 can be replaced with a carbamate functional group. The one pot reductive cyclization with indium reduced the number of steps, and compounds were synthesized with high yield. The general compound structure is added below (Fig. 1).

Murty et al. [13] reported that the long chain piperazine attached to benzoxazoles coupled with oxadiazoles have shown anticancer effect. The various oxadiazoles were prepared in simple steps and were coupled with the aryl piperazine derivatives using $\mathrm{KF}-\mathrm{Al}_{2} \mathrm{O}_{3}$ with acetonitrile as a solvent at $80^{\circ} \mathrm{C}$ heating. The cytotoxicity of the compound synthesized was checked on five human cancer cell lines. The $\mathrm{IC}_{50}$ values were determined on cancer cell lines of different origin like MCF-7 (breast), HeLa (cervical), HepG2 (liver), A431 (skin), and A549 (lung). All the compounds showed $\mathrm{IC}_{50}$ value less than 100 in MCF-7 cell line out of which $8 \mathrm{a}, 8 \mathrm{e}, 8 \mathrm{j}$, and $8 \mathrm{t}$ were observed to be more cytotoxic as compared to others. Few of the compounds which were having benzothiazole backbone instead of benzoxazole have a very good effect on MCF-7 cell line.

The compounds which have an amide linkage have a high cytotoxic effect over the A431 cell line (Fig. 2). All the compounds synthesized showed good results towards the A431 cell line as compared to other cell lines.

\section{Benzoxazole-1,3,4-oxadiazole moiety}

1,3,4-Oxadiazole [14] are a potent moiety to show a variety of biological activity. A few more amide compounds benzoxazole-1,3,4-oxadiazole compounds [15] were prepared (Fig. 3), and their anti-cancer activity was screened against 4 human cancer cell lines involving A549 (lung cancer), MCF-7 (breast cancer), A-375 (melanoma cancer), and HT-29 (colon cancer) using CA-4 as a positive

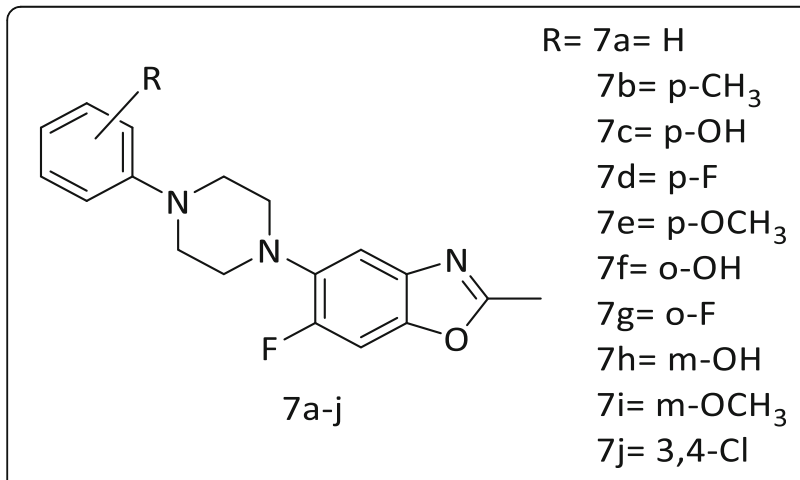

Fig. 1 Benzoxazole-piperizine derivatives

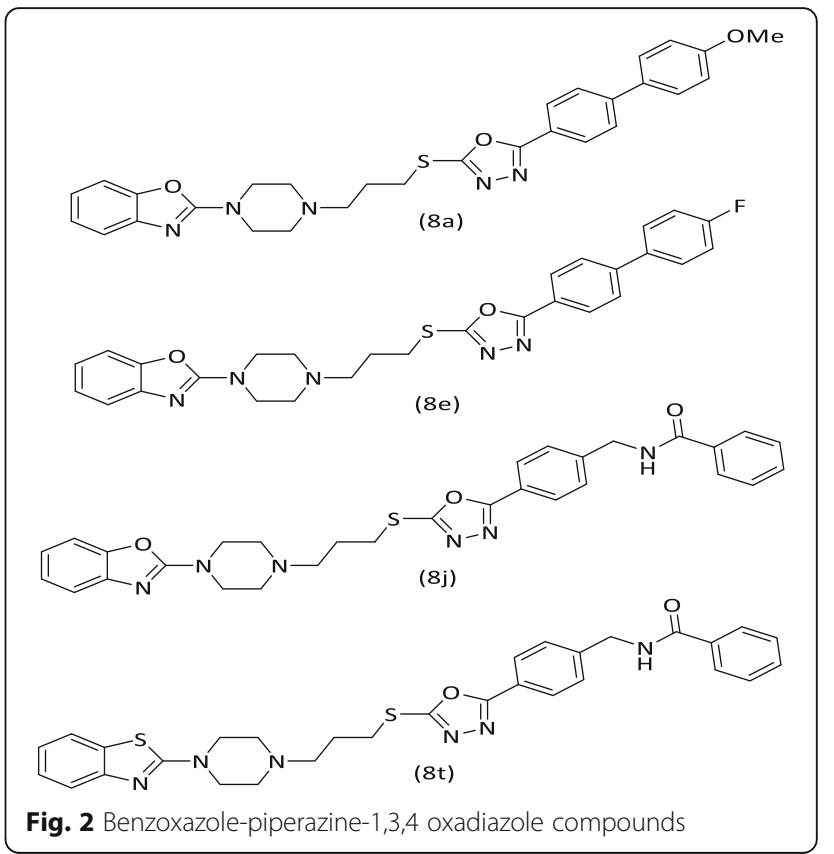

control. Off these synthesized compounds, it was observed that compounds $12 \mathrm{~b}, 12 \mathrm{c}$, and $12 \mathrm{~g}$ are showing anticancer activity against HT-29 cancer cell line, and the results are better than the standard drug. Few other compounds $12 \mathrm{~b}, 12 \mathrm{f}, 12 \mathrm{~g}$ and $12 \mathrm{i}$ were observed to be very active towards MCF-7 cancer cell lines. $12 \mathrm{~b}$ and $12 \mathrm{i}$ were observed to be active against A-549 cell lines. Compound $12 \mathrm{~b}$ has shown very good activity against HT-29, MCF-7, and A-549 cell lines.

\section{Benzoxazole-1,2,4-oxadiazole moiety}

1,2,4-Oxadiazole $[16,17]$ derivatives are well reported in literature to show anti-proliferative activity. Benzoxazole fused with benzofuran and 1,2,4-oxadiazole [18] (Fig. 4) was synthesized in minimum steps and high yields, and cytotoxicity activity was determined against human breast cancer (MCF-7), lung (A549), melanoma (A375), and colon (HT-29) cell lines with combretastatin-A4 as a positive control. Compounds 11b, 11c, 11d, 11g, 11h, and $11 \mathrm{i}$ were having more potent activity as compared to the positive control.

\section{Benzoxazole-pyrazolinone derivative}

New derivatives of benzoxazole, benzothiazole, and benzimidazole derivatives [19] (Fig. 5) were prepared. It was observed that without substitution at $\mathrm{N}-2$, the compounds show very poor anti-proliferative activity as compared to substitution at $\mathrm{N}-2$ of pyrazolinone.

Phenyl and acetyl substitution was done on the N-2 of pyrazolinone, and it increases the antiproliferative activity of the compounds. The acetylated compound (Fig. 6) was arranged as per their activity $12 \mathrm{a}>12 \mathrm{~b}>12 \mathrm{c}$ 


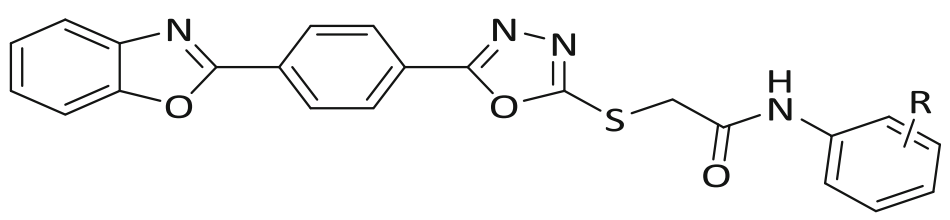

12a, $\mathrm{R}=\mathrm{H}$

12c, $R=4-$ methoxy

12e, $\mathrm{R}=4$-bromo

$12 \mathrm{~g}, \mathrm{R}=4$-nitro

$12 \mathrm{i}, \mathrm{R}=4$-cyano
$12 \mathrm{~b}, \mathrm{R}=3.4,5$ trimethoxy

$12 \mathrm{~d}, \mathrm{R}=4$-Chloro

12f, $R=4$-fluoro

$12 \mathrm{~h}, \mathrm{R}=4$-methyl

$12 \mathrm{j}, \mathrm{R}=3,5$ dimethoxy

Fig. 3 Benzoxazole-1,3,4 oxadiazole derivatives

according to their $\mathrm{IC}_{50}$ value. Now if the substitution was changed from acetyl to phenyl, then $13 \mathrm{~b}>13 \mathrm{a}>$ $13 \mathrm{c}$ according to their $\mathrm{IC}_{50}$ value.

These N-2-substituted pyrazolinone derivatives were found to be very active towards MCF-7 and A-549 cell lines. Compound 12a was found to be the most active compound against MCF-7 and A-549 cell lines with half maximal inhibitory concentrations $\left(\mathrm{IC}_{50}\right)=6.42$ and $8.46 \mu \mathrm{M}$.

The docking study of these compounds explains very well the interaction of the structural features and binding patterns of the compounds inside the active sites with the residual amino acids.

\section{Benzoxazole-triazole derivative}

Various other heterocycles were attached with the benzoxazole moiety to evaluate the anticancer activity. It was observed that benzoxazole and triazole have a wide activity spectrum, and, hence, Srivastava and team [20] (Fig. 7) have developed a one pot multicomponent reaction to prepare benzoxazole-triazole scaffolds which when evaluated for anticancer activity against HeLa, SKBr3, and HepG2 cancer cell lines have shown very interesting activity. The synthesis of benzoxazole-linked triazoles was rationalized in two sequential steps in one pot. This involved an in situ generation of alkyne from the corresponding dibromo-olefin precursor through $\mathrm{C}-\mathrm{H}$ activation of benzoxazole at $\mathrm{C}-2$ position. This was followed by 1 , 3-dipolar cycloaddition between the alkyne and benzyl azide to form the triazole ring. The reaction are copper iodide-mediated involving lithium tert-butoxide as a base and heating at $120^{\circ} \mathrm{C}$ in the first step followed by addition of benzyl azide and heating at $150^{\circ} \mathrm{C}$ for another $12 \mathrm{~h}$. These series of compounds were screened with HeLa, SKBr3, and HepG2 cancer cells, and they were observed to have potential anticancer activity. Compound $4\{2,2,2\}$ has been identified to have potent cytotoxic effect against cancer cell lines: HeLa, SKBr3, and HepG2, and is comparable to the control daunomycin.

Similarly, new series of fused benzoxazole and triazole compounds (Fig. 8) were synthesized, and anticancer activity [21] was evaluated against PBMC cell lines. The substitution was carried out at the thiol to prepare a series of compounds. Compound 12 was found to have

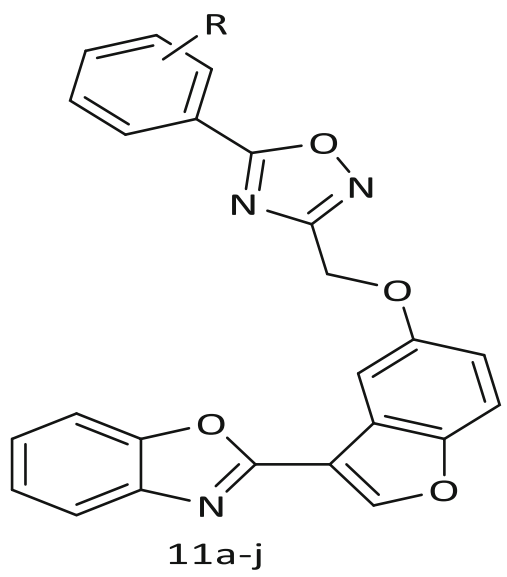

11a $\mathrm{R}=\mathrm{H}$

11b $\mathrm{R}=3,4,5$ trimethoxy

11c $\mathrm{R}=4-$ Methoxy

11d $\mathrm{R}=4$-Chloro

11 e $\mathrm{R}=4$-Bromo

11f $\mathrm{R}=4$-Fluoro

$11 \mathrm{~g} R=$ Nitro

$11 \mathrm{~h} \mathrm{R}=$ Cyano

11i $R=4-$ methyl

11j $R=4$-trifluoromethyl

Fig. 4 Benzoxazole-1,2,4 oxadiazole derivatives 


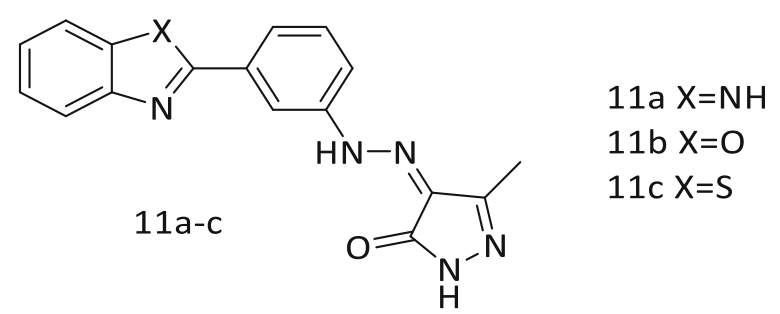

Fig. 5 Benzoxazole-pyrazolinone derivatives

the best activity; few of the compounds in the series were having a very good antibacterial activity.

Receptor tyrosine kinase is considered as an important therapeutic area of cancer as it is responsible for the cell growth and differentiation. Benzoxazole/benzimidazolelinked triazolotriazines [22] were synthesized, and anticancer activity was evaluated against A549, MCF-7, HepG2, and MDA-MB-231 cell lines. These compounds were selectively very potent towards HepG2 cell lines with compound $8 \mathrm{e}$ (Fig. 9) $\mathrm{IC}_{50}$ value very close to standard compound crizotinib.

On similar lines, Dadashpour and group [23] also made some 1,2,3 triazole-fused benzoxazole compounds, and antimicrobial, antifungal, and anticancer activities were evaluated. Though these series of compounds showed very good antibacterial and antifungal activity, these compounds were unable to show relatively good anticancer activity.

\section{Benzoxazole-combretastatin derivative}

Series of ten benzoxazole derivaties of combretastatin A4 [24] (Fig. 10) were synthesized and were evaluated against various cancer cell lines like Coco-205 (colon), A-549 (lung), and MCF-7 (breast) cell line, and interestingly, it was observed that compound $8 \mathrm{~d}$ was more potent than the standard compound against MCF-7 and A549 cell lines. Combretastatin A-4 is a natural product and was isolated from South African willow tree Combretum caffrum in 1989, and it shows anticancer activity against various cancer cell lines in nanomolar concentration. The structure of these new compounds was based on the structure of Combretastatin natural product, and cytotoxicity activity was studied.

The synthesis of these compounds was started from substituted phenyl acetic acid and substituted benzaldehyde followed by cyclization with amino phenol to get benzoxazole. The synthesized compounds were evaluated against selected cell lines like Colo-205 (colon), A549 (lung cancer), and MCF-7 (breast) by using SRB assay, and results show that compound $8 \mathrm{~d}$ has shown better activity than standard in 2 of the cell lines (MCF7 and A-549).

Few more benzoxazole-linked combretastatin compounds (Fig. 11) were synthesized [25] which were not structurally very different from the previous compounds and were tested against three human cancer lines breast (MCF-7), lung (A549), and melanoma (A375). Most of these compounds showed moderate anti-cancer activity, but compounds $11 \mathrm{~g}, 11 \mathrm{~h}, 11 \mathrm{l}, 11 \mathrm{~m}$, and $11 \mathrm{n}$ have shown very potent activity. Molecular docking study was carried out for these compounds, and $11 \mathrm{~g}$ and 111 were observed to have strong binding interaction with the receptor.

\section{Bisbenzoxazole derivative}

Few other natural-occurring substances also show cytotoxicity activity. Bis(benzoxazole) natural products UK-1 and AJI9561 (Fig. 12) have already been reported to have cytotoxic activity [26, 27]. Kumar et al. [28] subsequently reported the activity of UK-1 against a wide range of human cancer cell lines.

Both UK-1 and AJI9561 were reported to possess growth inhibitory activity against the murine cancer cell line P388. UK-1 though has a very strong antiproliferative activity but does not inhibit the growth of gram-positive and gram-negative bacteria, fungi, or yeast. UK-1 exhibits a wide spectrum of potent anticancer activity against leukemia, lymphoma, and certain solid tumor-derived cell lines, with $\mathrm{IC}_{50}$ values of as low as $20 \mathrm{nM}$. The natural product of bis(benzoxazole), UK-
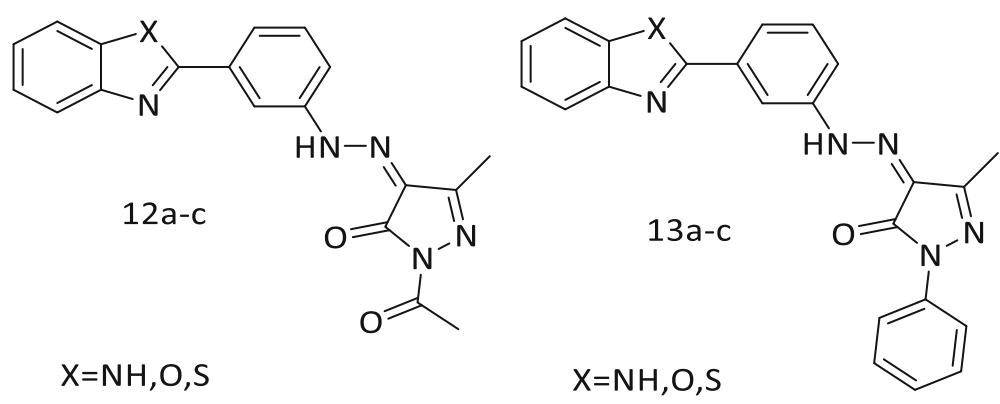

Fig. 6 Benzoxazole-pyrazolinone derivatives 


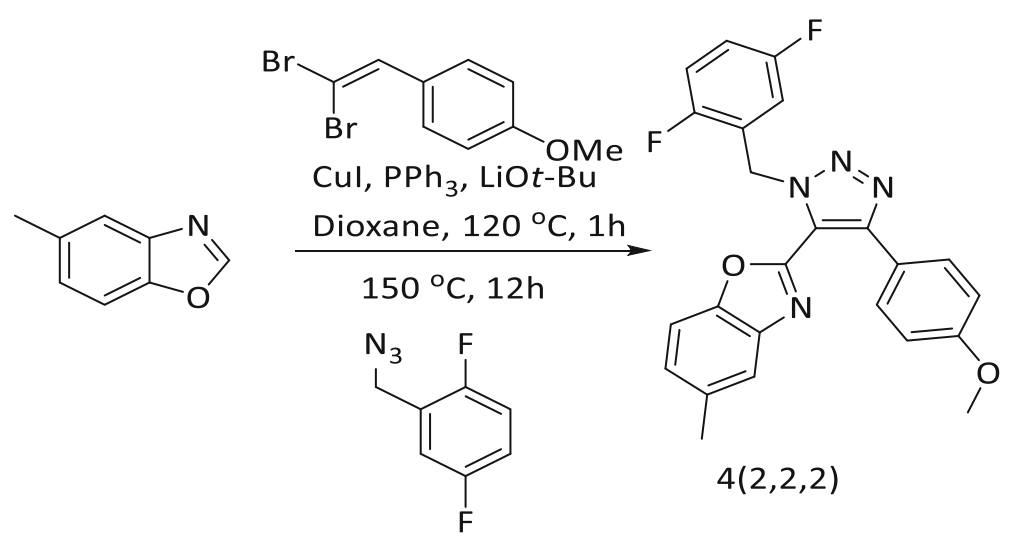

Fig. 7 Benzoxazole-triazole derivatives

1, has potential for use against cancer cell lines. The analog of UK-1 in which the carbomethoxy-substituted benzoxazole ring was replaced with a carbomethoxysubstituted benzimidazole ring was inactive against human cancer cell lines and the two strains of $S$. aureus. In contrast, a simplified analog in which the carbomethoxysubstituted benzoxazole ring of the UK-1 was replaced with a carbomethoxy group was almost as active as UK1 against the four cancer cell lines examined but lacked activity against $S$. aureus. The metal-binding affinity of these synthesized compounds was studied, and it was observed that they demonstrate good binding towards $\mathrm{Zn}^{2+}$ and $\mathrm{Ca}^{2+}$ ions. The non-cytotoxic benzimidazole UK-1 analog binds $\mathrm{Mg}^{2+}$ ions 50-fold weaker than UK-1, whereas the simple benzoxazole analog binds $\mathrm{Mg}^{2+}$ ions nearly as well as UK-1. These results support a role of $\mathrm{Mg}^{2+}$ ion binding in the selective cytotoxicity of UK-1 and provide a minimal pharmacophore for the selective cytotoxic activity of the natural product.

Structurally similar bis(benzimidazole) [29] derivatives (Fig. 13) were synthesized and it was observed that compounds 17 and 18 exhibit potent anticancer activity. Interestingly, compound 16 which is the synthetic precursor of compounds 17-19 was found to be more potent than UK-1 against human lung (A-549) and epithelial (HeLa) carcinoma cell lines. Therefore, further work with UK-1, compounds 15-18, and their analogs must be conducted to determine whether such targeting is involved in the selective cytotoxicity of UK-1 and compounds $15-18$, and whether the promising spectrum of the in vitro anticancer activity of UK-1 and 15-18 reported herein is also reflected in vivo.

Bis(benzoxazole) natural product (UK-1) shows activity against a wide range of human cancer cell lines, therefore, a very similar compound 4-carbomethoxy-2(2'-hydroxyphenyl) benzoxazole [30] has comparative activity similar to the natural product UK-1 and also formed complexes with a variety of metal ions such as $\mathrm{Mg}^{2+}, \mathrm{Cu}^{2+}, \mathrm{Zn}^{2+}$. Analogs of 4-carbomethoxy-2-(2'hydroxyphenyl)benzoxazole that were prepared whose structure remain very similar to UK-1 were synthesised, and anticancer activity of these compounds were examined against breast and lung cancer cell lines. To check the ability of these synthesized analogs and UK-1 to coordinate with $\mathrm{Mg}^{2+}, \mathrm{Cu}^{2+}$, and $\mathrm{Zn}^{2+}$, spectrophotometric titrations were carried out in methanol.

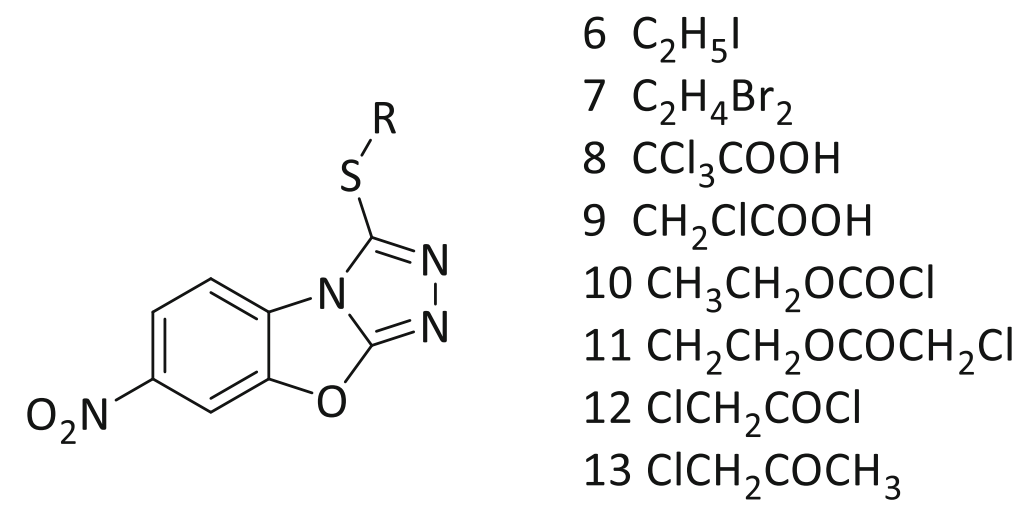

Fig. 8 Benzoxazole-fused triazole compounds 


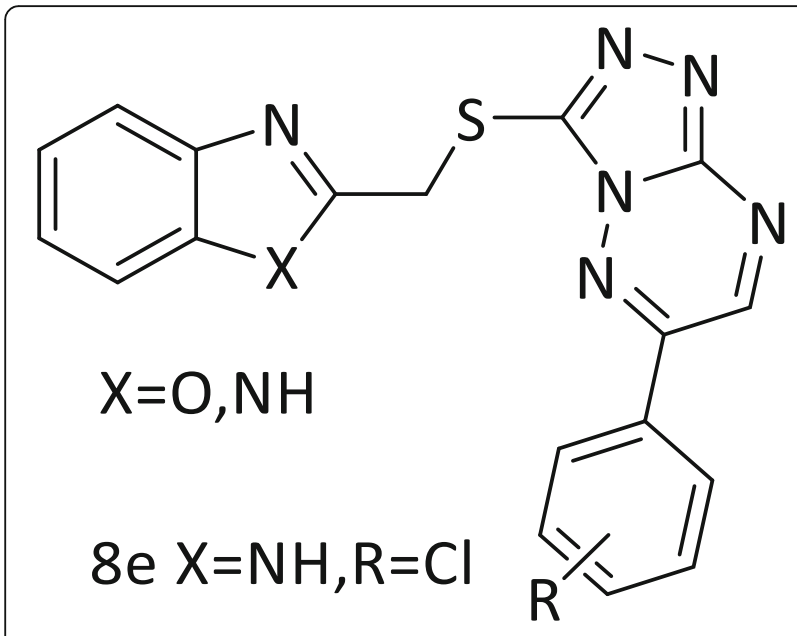

Fig. 9 Benzoxazole/benzimidazole-linked triazolotriazines

Although none of the new analogs were more cytotoxic than 4-carbomethoxy-2-(2'-hydroxyphenyl)benzoxazole, some analogs were identified that display similar cytotoxicity to this simplified UK-1 analog with improved water solubility. It was found that UK-1 and all of these new analogs (Fig. 14) bind $\mathrm{Cu}^{2+}$ ions better than $\mathrm{Mg}^{2+}$ ions, and the nature of the 4-substituent is important for the $\mathrm{Mg}^{2+}$ ion-binding ability of these 2-(2'-hydroxyphenyl)benzoxazoles. Previous studies of a limited number of UK-1 analogs demonstrated a correlation between $\mathrm{Mg}^{2+}$ ion binding ability and cytotoxicity; however, within this series of 4-substituted-2-(2'hydroxyphenyl)benzoxazoles, the variations in cytotoxicity do not correlate with either $\mathrm{Mg}^{2+}$ or $\mathrm{Cu}^{2+}$ ionbinding ability. These results, together with recent ESIMS studies of $\mathrm{Cu}^{2+}$-mediated DNA binding by UK-1 and analogs, indicate that UK-1 and analogs may exert their cytotoxic effects by interaction with $\mathrm{Cu}^{2+}$ or other

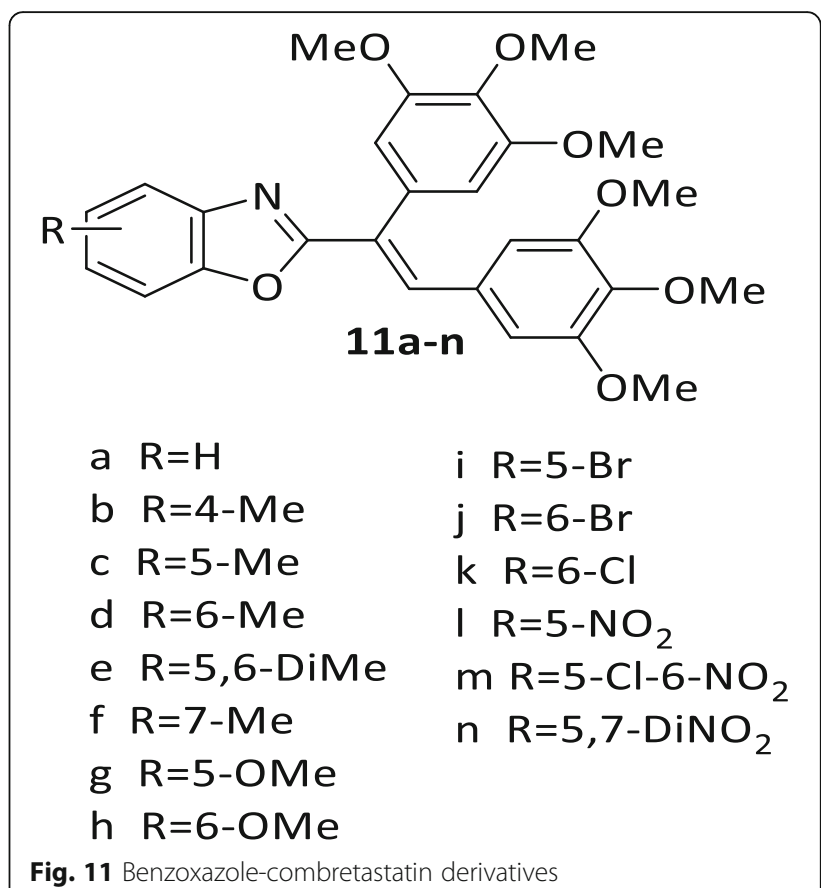

transition metal ions, rather than $\mathrm{Mg}^{2+}$, and that metal ion-mediated DNA binding, rather than metal ionbinding affinity, is important for the cytotoxic effect of these compounds. The potential role of $\mathrm{Cu}^{2+}$ ions in the cytotoxic action of UK-1 is further supported by the observation that UK-1 in the presence of $\mathrm{Cu}^{2+}$ displays enhanced cytotoxicity to MCF-7 and A549 cells when compared to UK-1 alone. This result is very promising in the future research activity. Few more structurally similar compounds to that of UK-1 were synthesised, and their anti-proliferative activity were studied.

A new benzoxazole derivative [31] which has a very similar structure to UK-1 was isolated from the

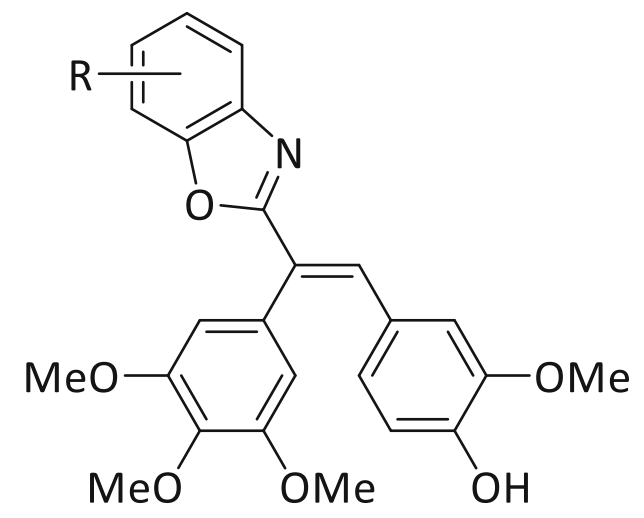

Fig. 10 Benzoxazole-combretastatin derivatives
$8 \mathrm{a} \mathrm{R}=\mathrm{H}$
$8 \mathrm{~b} \mathrm{R}=6-\mathrm{OMe}$
$8 \mathrm{c} R=5-\mathrm{OMe}$
$8 \mathrm{~d} R=5,6-\mathrm{OMe}$
8 e $\mathrm{R}=6 \mathrm{NO}_{2}$
8f $\mathrm{R}=5-\mathrm{Cl}, 6-\mathrm{NO}_{2}$
$8 \mathrm{~g} \mathrm{R}=, 5,6 \mathrm{NO}_{2}$
$8 \mathrm{~h} \mathrm{R}=5-\mathrm{Cl}$
8i $R=5-M e$
8j $R=5,6-M e$ 
<smiles>CC(=O)c1cccc2oc(-c3cccc4nc(-c5ccccc5O)oc34)nc12</smiles>

UK-1<smiles>Cc1cccc(O)c1-c1nc2cccc(-c3nc4c(C(=O)O)cccc4o3)c2o1</smiles>

AJI9561

Fig. 12 Structure of UK-1 and related compounds

Streptomyces species (strain Tü 6176) that was found to be having very strong growth inhibitory action against various human tumor cell lines. This Streptomyces species was collected from the soil sample from Brazil. This is called as nataxazole (Fig. 15), and it was prepared through batch fermentation of strain Tü 6176, the process engaging for $72 \mathrm{~h}$ before extraction with ethyl acetate and column purification over Sephadex LH-20 and Toyopearl HW-40 using $\mathrm{MeOH} / \mathrm{MDC}$ as mobile phase. The structure of this compound was elucidated by various NMR experiments. The inhibitory action of nataxazole (1) on the growth of tumor cells was compared with UK-1 and tested with various human tumor

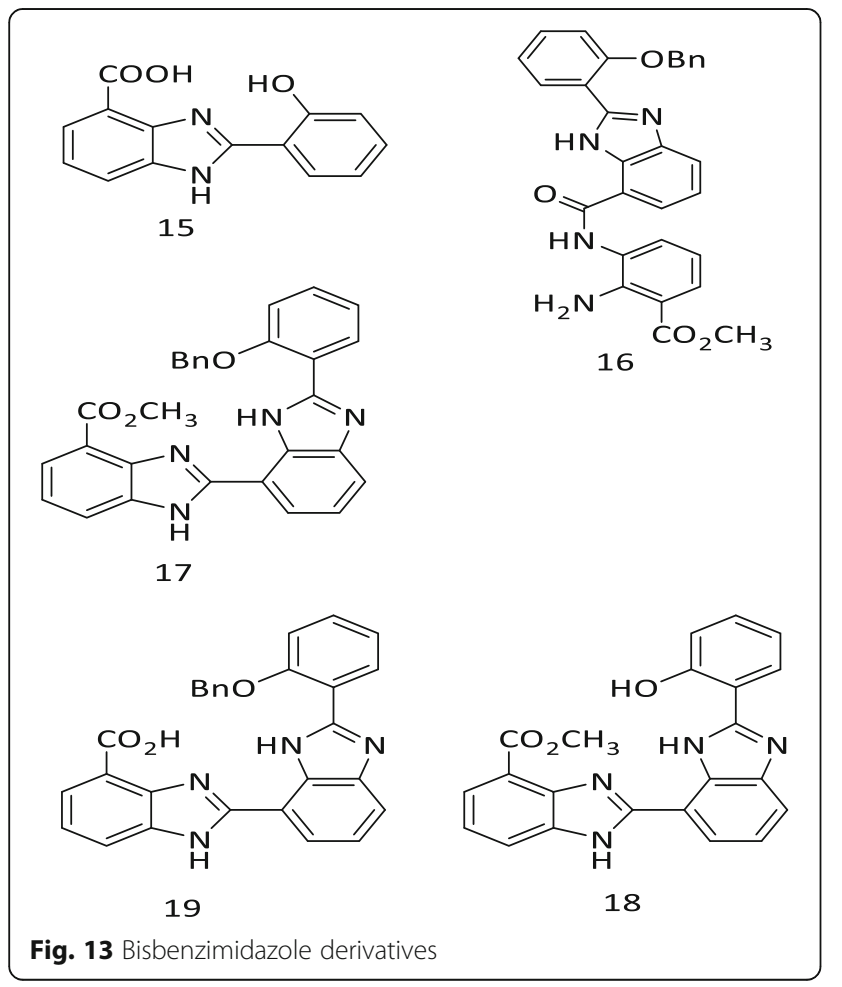

cell lines AGS (gastric adenocarcinoma), MCF7 (breast adenocarcinoma), and HepG2 (hepatocellular carcinoma). From the resulting concentration-activity curves, the GI50 (concentration at which half of the cells were inhibited in their growth) and TGI values (concentration at which a total inhibition of cell growth was observed) were obtained. The cytotoxic activity of 1 is somewhat better than UK-1 against AGS cells $\left(\mathrm{GI}_{50} 0.4 \mathrm{~m} \mathrm{~g} / \mathrm{ml}\right.$ vs. $0.8 \mathrm{mg} / \mathrm{ml}$ for UK-1) and equal against MCF-7 and HepG2 cells. The cell-cycle analysis revealed that nataxazole (1) and UK-1 produce an accumulation of cells in $S$ phase and reduce the ratio of cells in the G2/M phase. These findings indicate that nataxazole and UK-1 may exert their inhibitory effect on cell growth by a similar mechanism of action.

A new series of bisbenzoxazole [32, 33] derivatives were prepared by heating 2 equivalents of 4-chloro 2aminophenol with substituted dicarboxylic acids in PPA. These bisbenzoxazole derivatives (Fig. 16) were then evaluated against human prostate (DU145) and breast cancer cell lines (MCF-7). The cell viability results indicated that both of these compounds have a significant effect on human prostate (DU145) and breast cancer (MCF-7) cell lines. To confirm the side effects of these compounds, these compounds were tested against mouse fibroblast cells L929, and they have shown antiproliferative effect on fibroblast cells in time- and dosedependent manner.

\section{2-Aryl-benzoxazole derivative}

In 2015, Sun and co-workers [34] isolated a new series of compounds from the halophilic bacterial strain Nocardiopsis lucentensis DSM 44048 and tested their cytotoxicity against a panel of human tumor cell lines, and these compounds were known as nocarbenzoxazoles, and structures of these compounds were based on 2-aryl benzoxazole. Of these compound, isolated nocarbenzoxazoles-F (1) and nocarbenzoxazole G (2) 
<smiles>[R]C(=O)c1cccc2oc(-c3ccccc3OCc3ccccc3)nc12</smiles>

6. $\mathrm{R}=\mathrm{OEt}$

7. $\mathrm{R}=\mathrm{NHMe}$

8. $\mathrm{R}=\mathrm{NHBu}$

9. $\mathrm{R}=\mathrm{NH}\left(\mathrm{CH}_{2}\right)_{6} \mathrm{OH}$

10: $\mathrm{R}=\mathrm{NH}\left(\mathrm{CH}_{2}\right)_{2} \mathrm{O}\left(\mathrm{CH}_{2}\right)_{2} \mathrm{OH}$

11. $\mathrm{R}=\left(\mathrm{OCH}_{2} \mathrm{CH}_{2}\right)_{4} \mathrm{OH}$<smiles>[R]C(=O)c1cccc2oc(-c3ccccc3O)nc12</smiles>

12. $\mathrm{R}=\mathrm{OEt}$

13. $\mathrm{R}=\mathrm{NHMe}$

14. $\mathrm{R}=\mathrm{NHBu}$

15. $\mathrm{R}=\mathrm{NH}\left(\mathrm{CH}_{2}\right)_{6} \mathrm{OH}$

16. $\mathrm{R}=\mathrm{NH}\left(\mathrm{CH}_{2}\right)_{2} \mathrm{O}\left(\mathrm{CH}_{2}\right)_{2} \mathrm{OH}$

17. $\mathrm{R}=\left(\mathrm{OCH}_{2} \mathrm{CH}_{2}\right)_{4} \mathrm{OH}$

Fig. 14 Analogs of UK-1

(Fig. 17) were observed to have selective activities of HepG2 and HeLa cell lines.

Later, Kim and team [35] have come up with a coupling process on benzoxazoles to prepare nocarbenzoxazole and observed that analytical data of synthetically prepared nocarbenzoxazole was not matching with the naturally isolated product, and revised structure of nocarbenzoxazole was validated by the total synthesis. A series of more 2-aryl benzoxazole (Fig. 18) was prepared and activity checked with HeLa cells and compound observed to be selective activity against HeLa cell lines and did not have any remarkable effect on other cell lines.

A series of imidazolinone and benzoxazole derivatives [36] were synthesized by the condensation of oxazolidinone derivatives with aniline and 2-hydroxyaniline. These compounds were further acetylated with acetic anhydride and chloroacetyl chloride to prepare acetyl derivative of the parent compounds. The compound synthesized was tested against various human cell lines, and the results revealed that imidazolinone and benzoxazole derivatives are potent against the cancer cell lines. In particular, it was found that the benzoxazole derivatives were more potent than imidazolinone derivatives. The biological results obtained for these compounds confirm that they are most potent against the human breast tumor cells (MCF-7) and human hepatocellular cancer cells (HepG2).

A new series involving benzothiazoles and benzoxazoles [37] was synthesized using 4-benzothiazol-2-ylphenylamine and 4-benzoxazol-2-yl-phenylamine (Fig. 19) as starting materials. The first series of compounds involve Schiff base formation with various aldehydes, and the second series involves the condensation of 4benzothiazol-2-ylphenylamine and 4-benzoxazol-2-ylphenylamine with chloroacetyl chloride followed by displacement of chloro with various amines. All these compounds which were synthesized were evaluated for their antitumor activities against various human breast cancer cell lines mainly MCF-7 and MDA-231. All the compounds synthesized showed antitumor activity especially the N-methylpiperazine-substituted compounds mainly compound $6 \mathrm{c}$ and $6 \mathrm{f}$. The docking results of the

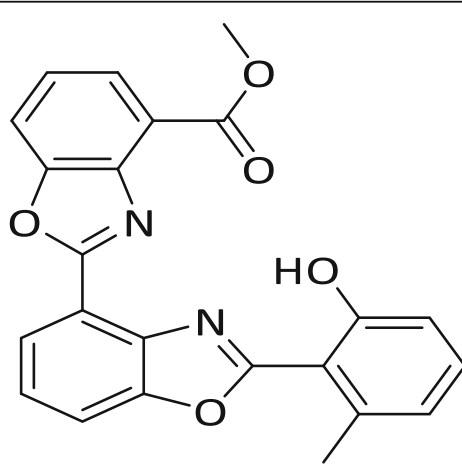

Nataxazole (1)

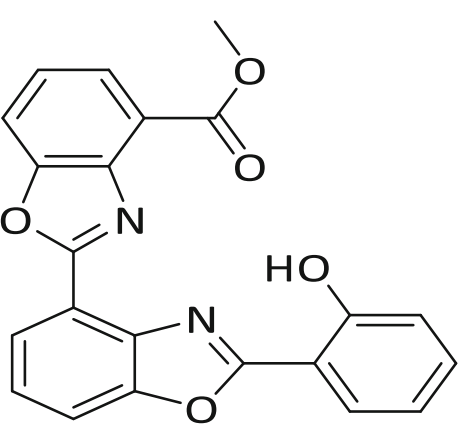

UK-1

Fig. 15 Structure of nataxazole and UK-1 


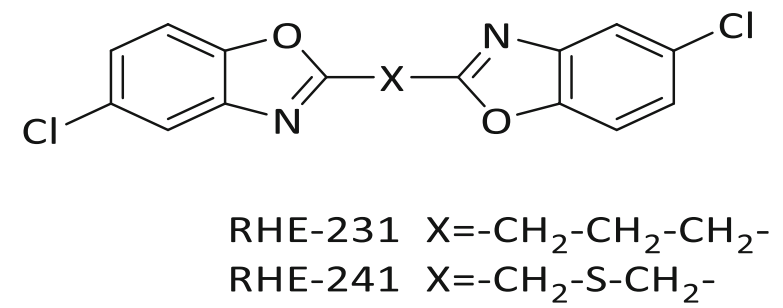

Fig. 16 Bisbenzoxazole derivatives

synthesized compounds were seen against epidermal growth factor receptor, and these compounds show very good interaction against them.

Further, a new series of hybrid compound [38] of benzothiazole-pyrazole and benzoxazole-pyrazole compounds (Fig. 20) were synthesized, and their anticancer activity were evaluated. In comparison to celecoxib, the pyrazole moiety was replaced with pyrazolinone, linked to benzothiazole or benzoxazole at $\mathrm{C} 4$ with different substituents at C3 aiming to obtain new hybrids useful as anticancer active agents. The synthesis of these compounds was started through very simple precursors like 2-aminophenol and 2-amino thiol which were condensed with 4-substituted benzoic acid.

The new hybrids were screened against lung, breast, and liver cancer cell lines (A549, MCF7, and Hep3B), in addition to normal fibroblast cells. Compound 13a was the most active and selective one on the lung cancer cell line (A549); its $\mathrm{IC}_{50}$ and SI values were $2.4 \mu \mathrm{M}$ and 83.2, respectively. Compound 14b was active on MCF-7 with the best selectivity towards this cell line. The new derivatives were screened for their inhibitory activity against COX enzymes; the obtained results revealed that<smiles>OCc1ccc2oc(-c3ccc(O)cc3)nc2c1</smiles>

\section{nocarbenzoxazole $F(1)$}<smiles>COc1cc(O)ccc1-c1nc2cc(CO)ccc2o1</smiles>

nocarbenzoxazole G (2)

Fig. 17 Nocarbenzoxazole $F$ and $G$<smiles>COc1cc(O)ccc1-c1nc2cc(CO)ccc2o1</smiles>

\section{Reported nocarbenzoxazole G}<smiles>COc1cc(-c2nc3cc(CO)ccc3o2)ccc1O</smiles>

\section{actual nocarbenzoxazole $\mathrm{G}$}

Fig. 18 Reported vs. actual nocarbenzoxazole $\mathrm{G}$

compounds $13 \mathrm{a}$ and $14 \mathrm{~b}$ were more active inhibitors for COX-2 than celecoxib.

\section{Benzoxazole-hydrazone derivative}

A series of benzoxazole-5-carbohydrazide derivatives [39] (Fig. 21) were prepared by condensation with different substituted isatin compounds. These derivatives were further checked with various in vitro anticancer cell lines like HeLa, IMR-32, and MCF-7 cancer cell lines using MTT method. These compounds were observed to be active against all the three cell lines. From the initial study, it was observed that the compounds having electron-withdrawing group have a better biological activity as compared to the compounds which are not

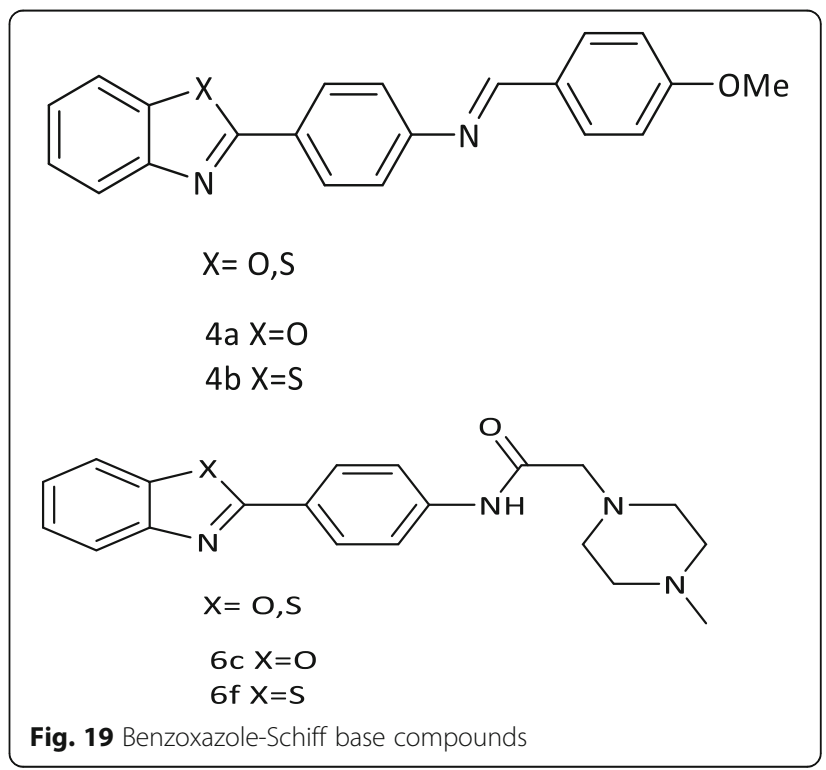




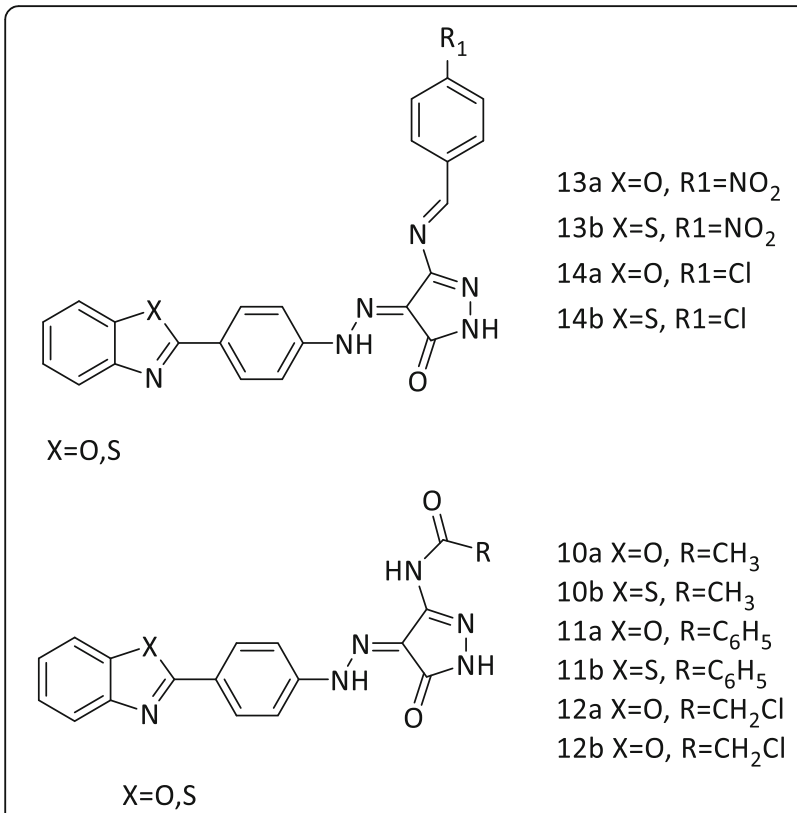

Fig. 20 Benzoxazole/benzothiazole-pyrazolinone derivatives

substituted. Other observation in the biological activity was, those compounds which have a substitution at C-5 on isatin moiety especially with different halides rather than C7 have a better biological activity. This information might help in the development of anticancer in future. The general structure of the compound is added below.

Hydrazone moiety plays a very important role in the anticancer drug development. New benzoxazole-based hydrazine derivatives were designed [40] (Fig. 22). Synthesized and in vitro cytotoxic effects were diagnosed on C6 rat glioma and NIH/3 T3 mouse embryonic fibroblast cell lines followed by flow cytometry-based apoptosis detection in C6 cell line. The compound 3g looks out to be a promising candidate for further studies.

\section{2-Thiobenzoxazole derivative}

It was previously reported [41] that benzothiazole derivative compounds have shown very impressive anticancer in vitro activities, and based on that, some compounds were synthesized by Wang et al. Compounds $1 \mathrm{a}$ and $1 \mathrm{~b}$ (Fig. 23) show very poor solubility and<smiles>[R]c1cc([R2])c2c(c1)/C(=N/NC(=O)c1ccc3oc(N)nc3c1)C(=O)N2</smiles>

Fig. 21 Benzoxazole-5-carbohydrazide derivatives

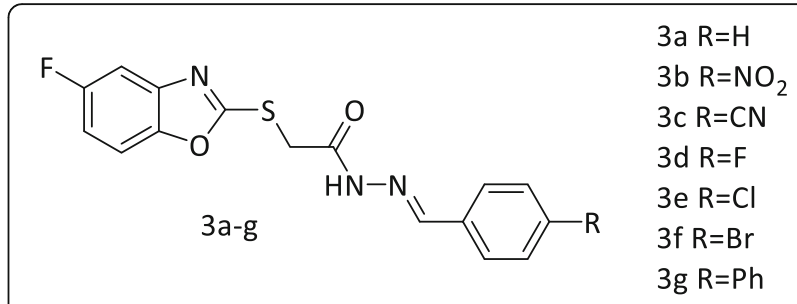

Fig. 22 Benzoxazole hydrazone derivatives

show moderate inhibition against HepG2 and MCF-7 cell lines, and hence, the lead optimization of compound $1 \mathrm{a}$ and $1 \mathrm{~b}$ were done.

To increase the solubility of these compounds, Nmethylpiperazine was introduced in position 2 and position 6 (Fig. 24) [42]. The results were impressive; the modified compounds have shown very comparative results as compared to compound 1a with better solubility. It was also noticed that in compound $1 \mathrm{e}$ where the benzyl group was replaced with $\mathrm{N}$-methylpiperazine group leads to the total loss of activity of the compound. The introduction of $\mathrm{N}$-methylpiperazine substituent at the 6position (1e) had a detrimental effect on the potency, that is, about 20-50-fold decrease in potency, compared with that of 1a. These results gave indication that the $\mathrm{N}$ methylpiperazine was well tolerated in 2-position so benzothiazole moiety was replaced with benzoxazole and benzimidazole, and it was to the delight that these new series of novel compounds still retain their anticancer activity.

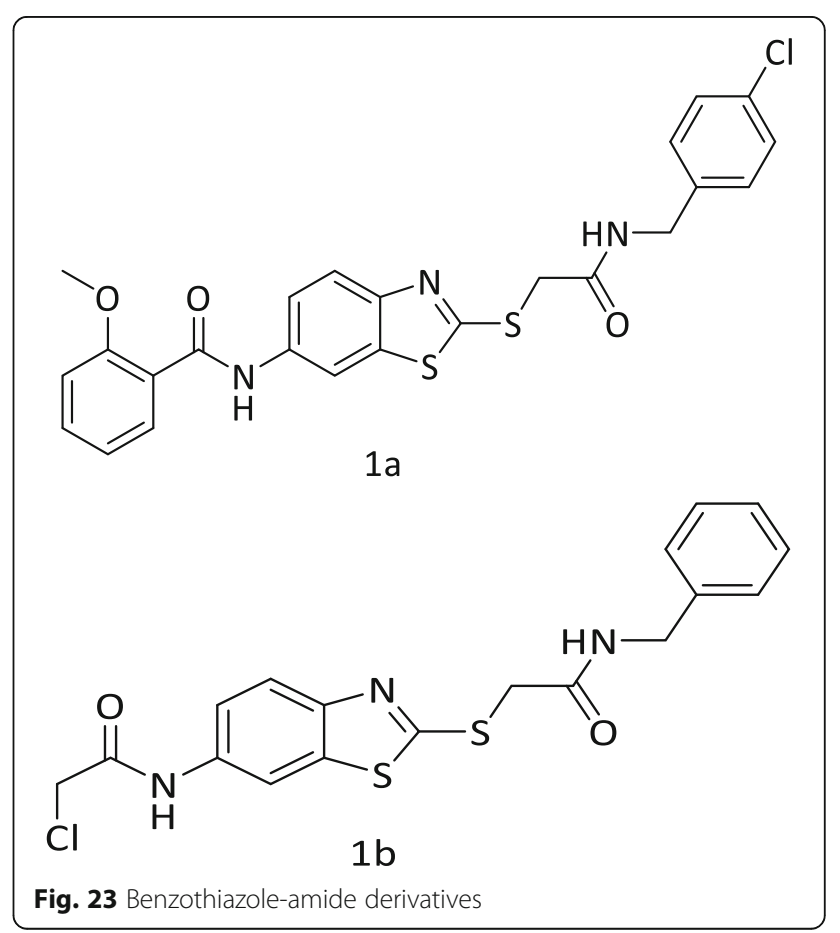




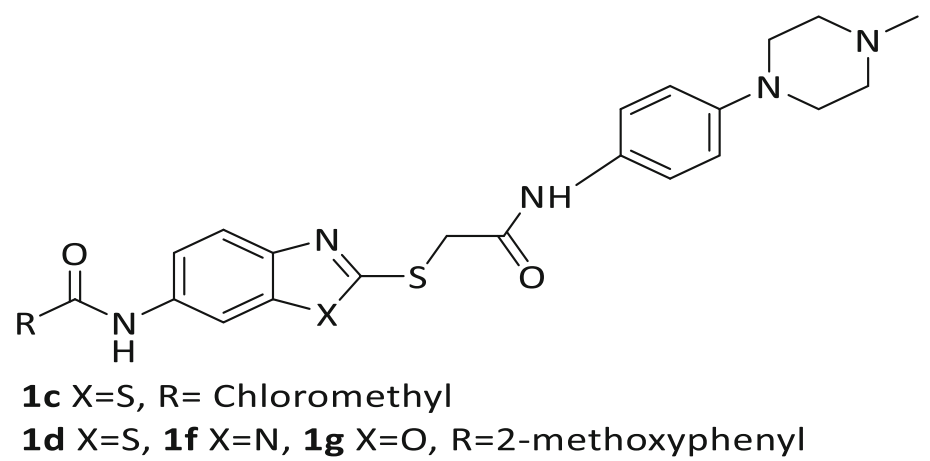<smiles>CN1CCN(c2ccc(C(=O)Nc3ccc4nc(SCC(=O)NCc5ccc(Cl)cc5)sc4c3)cc2)CC1</smiles>

Fig. 24 Benzothiazole/benzoxazole amide derivatives

In the preliminary in vitro biological evaluation, the immunofluorescence staining of HCT116 cells indicated that $1 \mathrm{~d}, 1 \mathrm{f}$, and $1 \mathrm{~g}$ led to cytosolic vacuolization which was not induced by 1a at low micromolecular concentrations. These results were impressive and suggest that these optimized compounds might potentially constitute a novel class of anticancer agents, which could fuel further studies.

A new series of compounds [43] were prepared by linking benzothiazole, benzoxazole, and pyridine to a hydrophilic moiety like a glycoside. This presence of hydrophilic moiety increases the solubility of these heterocycles and an improved selectivity toward cancer cells which are known to be specifically enriched in carbohydrate receptors such as lectins. The structure of these compounds was well confirmed through ROESY, DFQCOSY, HMBC, and HMQC NMR spectra. The biological activity of these compounds confirms that these compounds were not that effective against anticancer cell lines.

The synthesis of a range of 2-phenyl-benzothiazoles, -benzoxazoles, and -chromen-4-ones [44] related to the potent antitumor lead compound 2-(3,4-dimethoxyphenyl)-5-fluorobenzothiazole has been accomplished. Evaluation against the MCF-7 and MDA 468 breast cancer cell lines revealed compounds within the new series with potent (submicromolar $\mathrm{GI}_{50}$ ) activity in both cell lines (e.g., 9a, b and 12a, d). Although none of the new series was able to recapitulate the potent antitumor properties of 2-(3,4-dimethoxyphenyl)-5-fluorobenzothiazole, the new compounds were significantly more active than the structurally related benzimidazoles. Antitumor potency appeared to correlate with the emergence of a G2/M cell cycle block. For lead compound 2-(3,4dimethoxyphenyl)-5-fluorobenzothiazole, binding to the aryl hydrocarbon receptor appeared to play an important role in growth inhibition.

\section{Benzoxazole-pyrazole derivative}

Novel substituted pyrazolo-benzoxazole [45] compounds (Fig. 25) were synthesized, and the cytotoxicity activity was checked against MCF-7, KB, Hop62, and A549 cancer cell lines. The compounds with methoxy substitution at positions 5 and 6 were observed to have an excellent

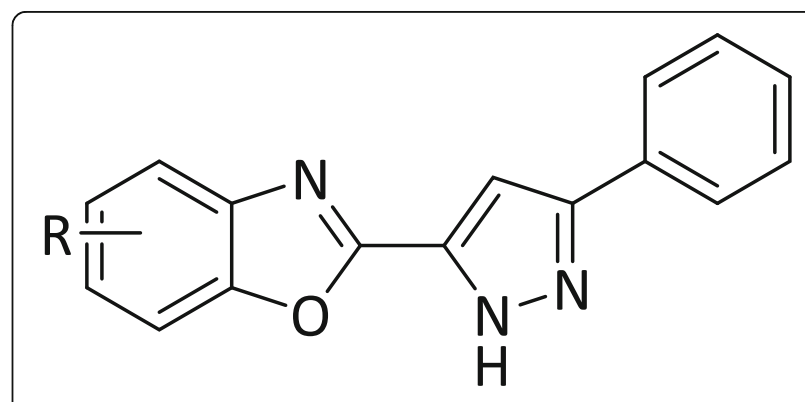

Fig. 25 Benzoxazole pyrazole derivatives 
anticancer activity. The compounds having nitro substitution at 6 position was observed to have very good antitumor activity against MCF-7 and A-549 cell lines. Compounds having nitro disubstitution at 5 and 7 was also found have very good anticancer activity against A549 cell lines. Few other compounds were also prepared where benzoxazole moiety was exchanged with benzofuran backbone, and anticancer activity was tested.

\section{Benzoxazole-quinoline derivative}

A one pot synthetic strategy for the synthesis of hybrid of benzoxazole with quinoline and quinoxaline compounds (Fig. 26) was employed to prepare some active anticancer compounds [46]. The synthesis involves heating substituted 2-aminophenols and corresponding aldehyde with equal equivalents of silica chloride for 3-4 h at $120{ }^{\circ} \mathrm{C}$ without any solvent. Molecular docking of these compounds revealed that these compounds inhibit enzyme protein tyrosine kinase. The cytotoxicity study of these compounds (4a-f) showed that these compounds are more potent towards breast cancer cell lines MCF-7 and MDA-MB-231 as compared to oral and lung cancer cell lines KB and A-549. The compound 4c was found to be very active and showed the maximum inhibition in the activity of enzyme tyrosine kinase. Molecular docking revealed that the compound $4 \mathrm{c}$ has formed 2 hydrogen bond interaction, one taking place with the nitrogen of benzoxazole with Thr-766 while the other through the nitrogen of quinoxaline with Met769 which corresponds to the active site of the enzyme.

\section{Benzoxazole derivative and VEGFR-2 inhibition}

The VEGF signaling pathway plays an important role in determining tumor angiogenesis [47]. Many studies have shown that the abnormal expression of VEGFR-2 in

$$
\begin{aligned}
& \text { 4a, R=5-Br, Ar=4-Nitrophenyl } \\
& \text { 4b, R=5-Br, Ar=4-Bromophenyl } \\
& \text { 4c, R=5-Br, Ar=Quinoxalinyl } \\
& \text { 4d, R=H, Ar=Quinoxalinyl } \\
& \text { 4e, R=H, Ar=2-Chloroquinolinyl } \\
& \text { 4f, R=5-Br, Ar=2-Chloroquinolinyl }
\end{aligned}
$$

Fig. 26 Benzoxazole fused with quinoxalin tumor cells is related to tumor growth and migration [48]. Therefore, inhibition of VEGF and VEGFR-2 signaling pathways plays a very important therapeutic target for tumor angiogenesis and subsequent tumor growth. Sorafenib is already approved as antiangiogenic drug [49, 50], and based on the structure, it was found out that major VEGFR-2 inhibitory compound has 4 main features, and 3 series of compounds with benzoxazole/benzothiazole backbone were synthesized [51] (Fig. 27), and

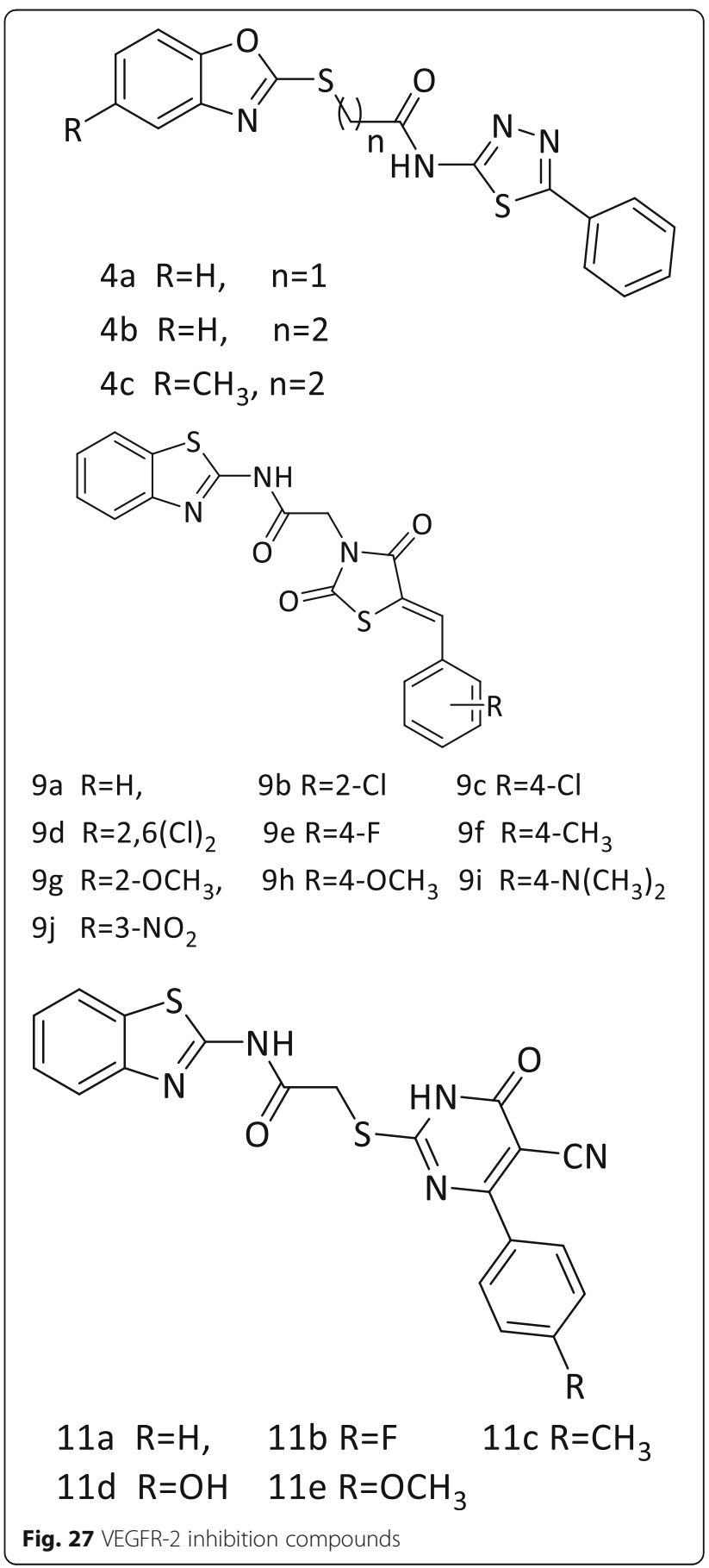


cytotoxicity was checked against various cancer cell lines HepG2, HCT-116, and MCF-7. Compound 4b was found to be very active against all the 3 cell lines. All the 3 series of compound were evaluated against VEGFR-2 inhibition, and compounds $4 \mathrm{~b}$ and $4 \mathrm{c}$ were found to have a very close value against standard Sorafenib compound.

Few more 6-amide-2-aryl benzoxazole and benzimidazole compounds [52] were synthesized based on the active site of VEGFR-2, and in vitro activity was checked. These compounds were seen to be more potent against HUVEC and HepG2 cancer cell lines as compared to A549 and MDA-MB-231 cancer cell lines. These 37 newly synthesized compounds were evaluated for antiangiogenesis capability by chick chorioallantoic membrane (CAM) assay. Compound 9d showed the most potent anti-angiogenesis activity. General structure of the 37 newly synthesized compound is added in Fig. 28.

The molecular docking of these compounds was studied, and it was found that compound $9 \mathrm{~d}$ is a type-II inhibitor of VEGFR kinase. These results were very promising and can be utilized in future for potential treatment of anti-angiogenesis.

\section{Benzoxazole-sulphamide derivative}

El-Helby et al. [53] developed few more hybrid compounds of benzoxazole-sulphamide side chains (Fig. 29), and they were tested against HepG2, HCT-116, and MCF-7 cell lines. All these compounds have shown very good activity against HCT-116 cell line. Compound 5e was the most potent compound which showed very good activity against all the 3 cell lines. The most potent compound of the series was tested against VEGFR-2 inhibition, and compounds $5 \mathrm{c}, 5 \mathrm{e}$, and $5 \mathrm{f}$ have shown very good activity. Compound $5 \mathrm{f}$ has shown $\mathrm{IC}_{50}$ value as low as $0.10 \pm 0.02 \mu \mathrm{M}$ which is the same to the standard drug sorafenib. The docking study revealed that all the compounds have the similar position and orientation side as the binding site of VEGFR-2.

It was suggested that overexpression of hGST P1-1 by human tumor cells is the main reason for the resistance of the anticancer drug [54]. So few compounds of benzoxazole-sulphamide (Fig. 30) were synthesized by

$$
\begin{aligned}
& \text { 3- } \mathrm{Br}, 4-\mathrm{Cl}, 3-\mathrm{F}-4-\mathrm{Cl}, 3 \mathrm{~F}-4-\mathrm{Br} \\
& \begin{array}{l}
\mathrm{R}=4-\mathrm{Cl}, 2 \mathrm{~F}, 2 \mathrm{Cl}, 2-\mathrm{Br}, 3-\mathrm{Br} \\
4-\mathrm{CH}_{3}, 4-\mathrm{OCH}_{3}
\end{array}
\end{aligned}
$$

Fig. 28 Benzoxazole/benzimidazole VEGFR-2 inhibition compounds

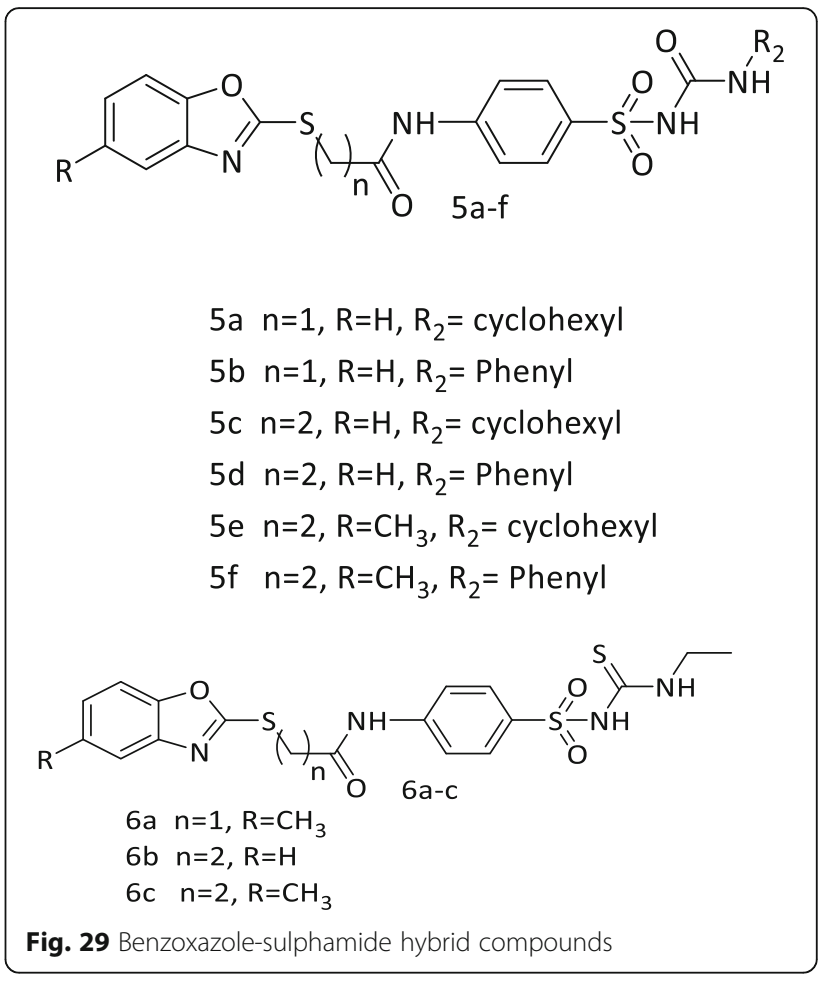

Oksuzoglu and team [55] which showed hGST P1-1 enzyme inhibition. A few modifications to the structure were also done to understand the effect of substitution on the activity of the compounds. These compounds were screened against HL-60 cancer cell lines. Compounds $1 \mathrm{~b}, 1 \mathrm{c}$, and $1 \mathrm{~d}$ were having better $\mathrm{IC}_{50}$ values than standard drug etoposide. Topo II plays a very important role in the cancer chemotherapy treatment. So all these compounds synthesized were checked if they could inhibit Topo II. Hence, molecular docking was done onto the active site of DNA Topo II enzyme (PDB: 3QX3) to understand the antitumor activity of these compounds.

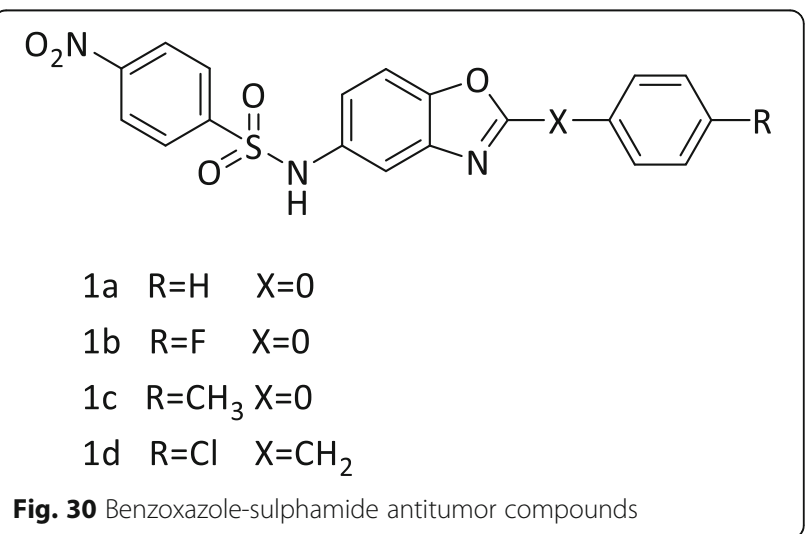


Fig. 31 Benzoxazole triazole compounds

\section{Benzoxazole-isoxazole-1,2,3-triazole derivative}

1,2,3-Triazole [56, 57] and oxazole [57, 58] are previously reported to have shown cytotoxic activity. Dadmal [59] and team have coupled this 1,2,3-triazole and oxazole moiety with benzothiazole and benzoxazole moiety (Fig. 31), and cytotoxic effect was evaluated against human cancer cell lines Hela (cervical) and A549 (lungs). Compounds $13 \mathrm{~g}, 13 \mathrm{~h}$, and $13 \mathrm{j}$ have shown very impressive results against standard drugs TAK-165 and GW610. It was also understood that these compounds induces apoptosis to cancer cell through caspasedependent apoptotic process.

\section{Benzoxazole-tetrazole derivative}

A new series of compound involving tetrazole coupled with benzoxazole [60] (Fig. 32) was synthesized, and anticancer activity was evaluated against MCF-7, Hop62, and A549 cell lines. The activity of these synthesized compounds was not that promising as compared to the standard Adriamycin, but compounds $9 \mathrm{~b}$ and $9 \mathrm{~g}$ were having the best anticancer activity in the lot.

\section{Benzoxazole-pyrimidine derivative}

Pyrimidine moiety has shown anticancer activity previously, so new series of Benzoxazole azo-pyrimidine [61] and benzimidazole azo-pyrimidine were synthesized by using very simple steps. Firstly, the 3-aminophenyl benzoxazole and benzimidazole were synthesized, and then, they were made into diazonium salt and coupled with diethyl malonate further this intermediate was cyclised with urea to prepare new variety of pyrimidine benzoxazole and benzimidazole hybrids (Fig. 33). The cytotoxic activity was evaluated against breast carcinoma (MCF-7), lung cancer (A549), human prostate cancer (PC-3), human pancreatic cancer (PaCa2), and colorectal adenocarcinoma (HT-29) cell lines. From the results, it was observed that benzoxazole compound 7a showed lower activity than benzimidazole compound $7 \mathrm{~b}$ in all cell lines. Docking study was done with COX-2 enzyme (PDB-1CX2) to explain the lower activity of compound $7 \mathrm{~b}$ as compared to compound $7 \mathrm{a}$, and it was curtained that compound-7a gets fitted well in the cavity and has better interaction therefore forms 3 hydrogen bonds whereas compound $7 \mathrm{~b}$ forms 2 hydrogen bond.

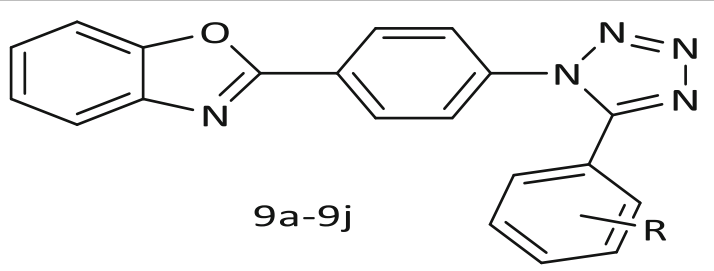

9a, $R=H$
$9 b, R=3,4,5$-trimethoxy
$9 c, R=4$-methoxy
9d, $R=4$-chloro
9e, $R=4$-bromo

9a, $\mathrm{R}=\mathrm{H}$

Fig. 32 Benzoxazole-tetrazole compounds

9f, $R=4$-fluoro

9g, $R=4$-nitro

9h, $R=3$-nitro

9i, $R=4$--trifluoromethyl

9j, R=4-methyl 


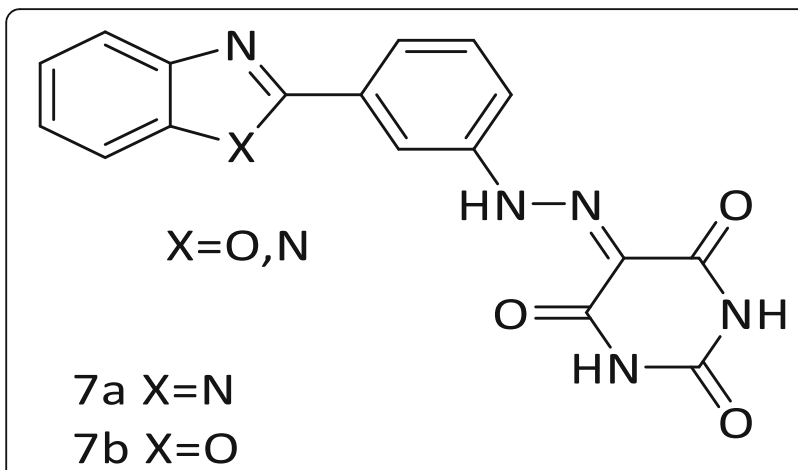

Fig. 33 Benzoxazole/benimidazole pymiridine-based hybrid compounds

Another series of pyrimidine-based compounds developed by Seenaiah and team [62] were hybrid compounds by coupling pyrimidine with benzimidazole, benzothiazole and benzoxazole (Fig. 34). These were linked to the pyrimidine moieties by thio, methylthio, and amine moieties. These synthesized compounds were studied for their antimicrobial activities and anticancer activity. From the series of 27 synthesized compounds, compound-22 was the most active compound, and compound-24 was most active against A549 cell lines with the $\mathrm{IC}_{50}$ value of $10.5 \mu \mathrm{M}$.

\section{Benzoxazole-phthalimide derivative}

Phthalimide core was coupled with benzoxazole/benzothiazole (Fig. 35) to prepare a new set of compounds. Though in previous occasion it was observed that phthalimide core compounds have shown teratogenic disorders, variation in the phthalimide structure could eliminate the side-effects and show promising anticancer activity [63]. These synthesized hybrid compounds [64] were evaluated through $\mathrm{IC}_{50}$ values against two human cancer cell lines HepG2 and MCF7. To check its effect against healthy cells, these compounds were screened against WI-38 cell lines. 5Fluorouracil and erlonitib were used as the standard against HepG2 and MCF7 cell lines respectively. It<smiles>Cc1cc(Sc2nc3ccccc3[nH]2)nc(SCc2nc3ccccc3[nH]2)n1</smiles>

Compound-22

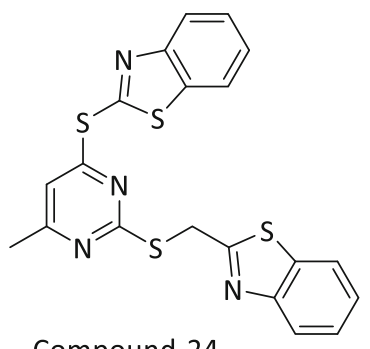

Compound-24
Fig. 34 Pyrimidine-benzoxazole/benzothiazole/benzimidazole compounds<smiles></smiles>

$$
\begin{aligned}
& \text { 5a } X=\mathrm{O}, \mathrm{R}=\mathrm{CH}_{3}, \mathrm{Y}=\mathrm{H} \\
& \text { 5b } X=\mathrm{O}, \mathrm{R}=\mathrm{CN}, \mathrm{Y}=\mathrm{H} \\
& \text { 5c } X=\mathrm{O}, \mathrm{R}=\mathrm{Cl}, \quad \mathrm{Y}=\mathrm{H} \\
& \text { 5d } X=\mathrm{O}, \mathrm{R}=\mathrm{H}, \quad \mathrm{Y}=\mathrm{COOH} \\
& \text { 5e } X=\mathrm{O}, \mathrm{R}=\mathrm{CH}_{3} \quad \mathrm{Y}=\mathrm{COOH} \\
& \text { 5f } X=\mathrm{O}, \mathrm{R}=\mathrm{Cl}, \quad \mathrm{Y}=\mathrm{COOH} \\
& 5 \mathrm{~g} X=\mathrm{S}, \mathrm{R}=\mathrm{CH}_{3} \quad \mathrm{Y}=\mathrm{H} \\
& \text { 5h } X=S, R=C N, \quad Y=H \\
& \text { 5j } X=S, R=C l, \quad Y=H \\
& 5 \mathrm{k} X=\mathrm{S}, \mathrm{R}=\mathrm{CH}_{3} \quad \mathrm{Y}=\mathrm{COOH} \\
& \text { 5I } X=S, R=C l, \quad Y=C O O H
\end{aligned}
$$

Fig. 35 Benoxazole/benimidazole phthalimide-based compounds

was observed that none of the compounds have shown cytotoxic activity against WI-38 cell lines and have shown potent anticancer activity against HepG2 and MCF7 cell lines in nanomolar to micromolar range. Both benzoxazole and benzothiazole derivatives $5 \mathrm{a}, 5 \mathrm{~b}$, and $5 \mathrm{k}$ exhibited 1.7 to 3 times more potent anticancer activity against HepG2 cell line than 5fluorouracil, which is a very promising result. Compounds $5 \mathrm{c}$ and $5 \mathrm{~g}$ were the most potent derivatives between the tested compounds. They showed $\mathrm{IC}_{50}$ values 9 and $6 \mathrm{nM}$ with 79 and 118 times more potent anticancer activity than erlotinib against MCF7 cell line.

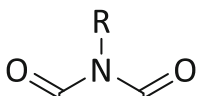

$$
\begin{aligned}
& =
\end{aligned}
$$

\section{Compound-5-10}

Fig. $\mathbf{3 6}$ C4 benzoxazole naphthalimide derivatives 


$$
\begin{aligned}
& \text { Sa, } \mathrm{Ar}=\mathrm{C}_{6} \mathrm{H}_{5} \\
& 5 \mathrm{~b}, 2-\mathrm{OHC}_{6} \mathrm{H}_{4} \\
& 5 \mathrm{c}, 4-\mathrm{FC}_{6} \mathrm{H}_{4}
\end{aligned}
$$

Fig. 37 Benzoxazole/benzothiazole quinolone compounds

\section{Benzoxazole-naphthalimide derivative}

The flat structure of the naphthalimide has an advantage of inserting into the DNA and thus compounds like amonafide and mitonafide had shown previously very promising results against various cancer cell lines. But these active compounds could not move ahead because of their toxicity [65], but it was reported that by modifying the N,N-dimethyl chain of mitonafide, the toxicity can be reduced [66]. Hence, some novel compounds were synthesized by condensing benzoxazole at $\mathrm{C} 4$ position of naphthalimide [67] (Fig. 36), and it was observed that the cytotoxicity of these compounds largely depends on the side chain. Compounds 9 and 10 were able to exhibit better cytotoxic activity against B16F10 cells as compound to compound 5-8, and the reason behind is largely due to the side chain. Compounds 9 and 10 show the same degree of cytotoxicity as that of amonafide.

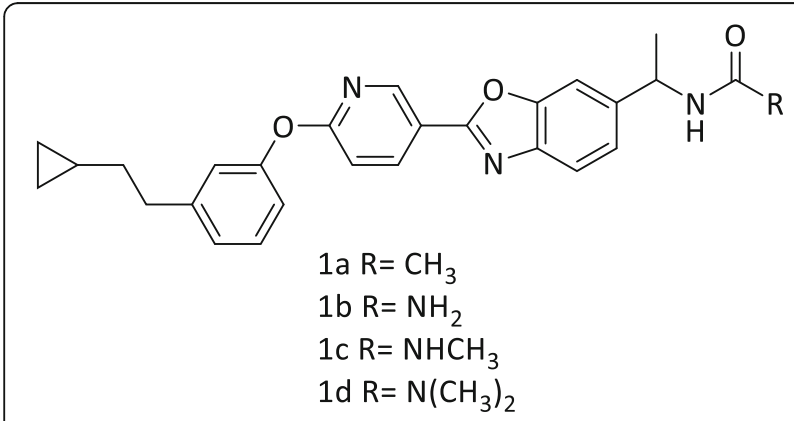

Fig. 38 Benzoxazole as ACC1 inhibitor

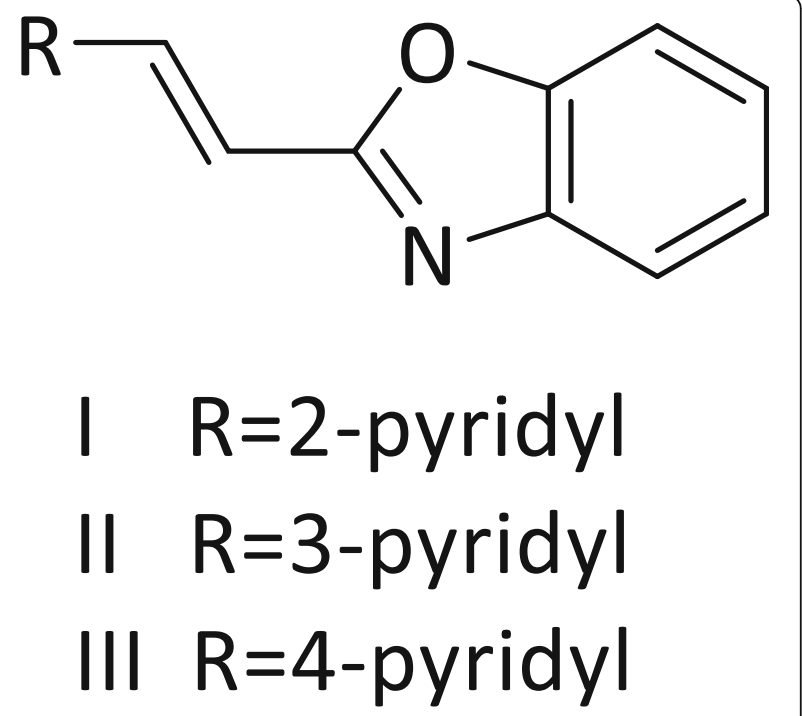

Fig. 39 Benzoxazole-pyridine moiety

\section{Benzoxazole-quinolone derivative}

Derivatives of quinolones [68] are confirmed to have anticancer effect. So new series was developed by condensing the quinolones with benzoxazole and benzothiazole moiety [69] (Fig. 37); after that, these compounds were screened for cytotoxicity activity against breast cancer cell lines. Compounds with thiazole connected to quinolones have shown better results as compared to compounds with benzoxazole associated with quinolones. Compounds $5 \mathrm{~h}$ and $5 \mathrm{l}$ were found to be showing the best activity as compared to the other compounds in the series. Hybrid compounds of benzoxazole with

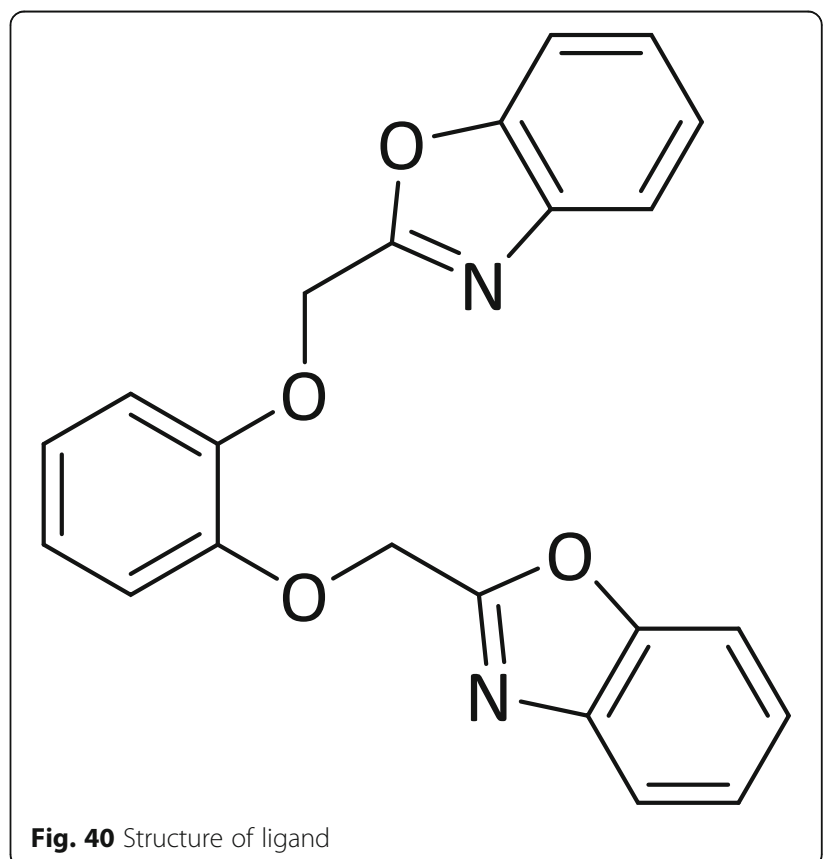




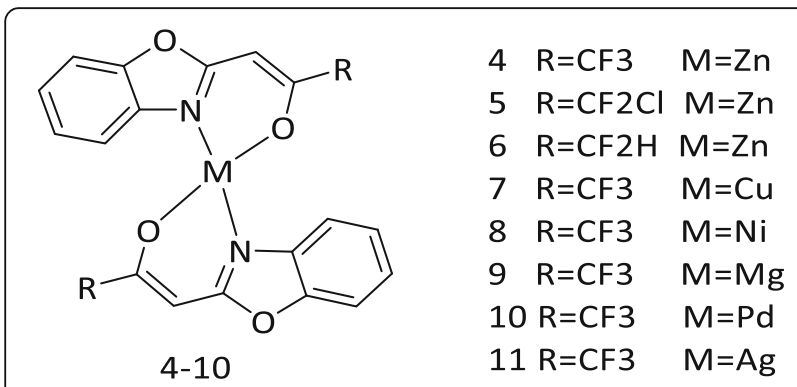

Fig. 41 2-Trifluoroacetonyl-benzoxazole metal complexes

quinolones were observed to be better antioxidant as compared to thiazole derivative.

\section{Benzoxazole-pyridine derivative}

Novel benzoxazole derivatives were prepared which were having improved selectivity towards mouse ACC1 against ACC2 [70]. ACC1 is overexpressed in human cancer cells; a number of mammalian ACC inhibitor were reported as dual $\mathrm{ACC} 1$ and $\mathrm{ACC} 2$ inhibitor or sometimes only ACC2 inhibitor but rarely ACC1 inhibitor. The current set of targets (Fig. 38) is reported to be only ACC1 inhibitor. Slight modifications in the structure of the compound have reduced the side effect of weight loss observed in compound 1a. Unsubstituted ureido compound $1 \mathrm{~b}$ has a better selectivity towards mouse ACC1 as compared to compound 1c and 1d.

Three novel pyridine-benzoxazole [71] derivatives (Fig. 39) were prepared, and anticancer activity was evaluated against HepG2 cell line. The 2-methyl benzoxazole derivative was coupled with pyridine-2,3 and 4 aldehyde to get the 2-pyridiyl, 3-pyridiyl, and 4-pyridiyl benzoxazole derivative. The crystal structure was studied, and antitumor activity was evaluated. The $\mathrm{IC}_{50}$ values of these compounds were 87.7, 9.6, and $33.5 \mu \mathrm{mol} / \mathrm{l}$ respectively.

\section{Benzoxazole-metal complexes}

A new ligand 2-((2-((benzo[d]oxazol-2-yl)methoxy)phenoxy)methyl)benzoxazole [72] (L) (Fig. 40) and its four transition metal complexes $\mathrm{M}\left(\mathrm{NO}_{3}\right)^{2} \mathrm{~L}(\mathrm{M}=\mathrm{Cu}, \mathrm{Co}, \mathrm{Ni}$, $\mathrm{Zn})$ were synthesized, and their characters were investigated. The single crystal structures of these complexes show that all of them have similar molecular structure, and the ligand exhibits good coplanarity after coordination with the metal ions. Further investigation of DNA binding indicates that both the ligand $\mathrm{L}$ and the complexes can bond to DNA by intercalation mode, and the latter possesses much stronger binding affinity. The cytotoxicity assays of all the compounds against four different tumor cell lines (A549, HepG2, K562, K562/ ADM) were evaluated by MTT assay. It was notable that the ligand was almost inactive against all the cell lines. However, all of the complexes exhibited considerable antitumor activity and cytotoxic specificity toward the tested cancer cell lines. $\mathrm{Cu}-\mathrm{L}$ showed much higher antitumor activity than other complexes did on all the cell lines.

Novel metal [Zn(II), Cu(II), Mg(II), Ni(II), Pd(II), and $\mathrm{Ag}(\mathrm{I})$ ] complexes of 2-trifluoroacetonyl-benzoxazole [73] (Fig. 41) were synthesized, and multidrug reversing

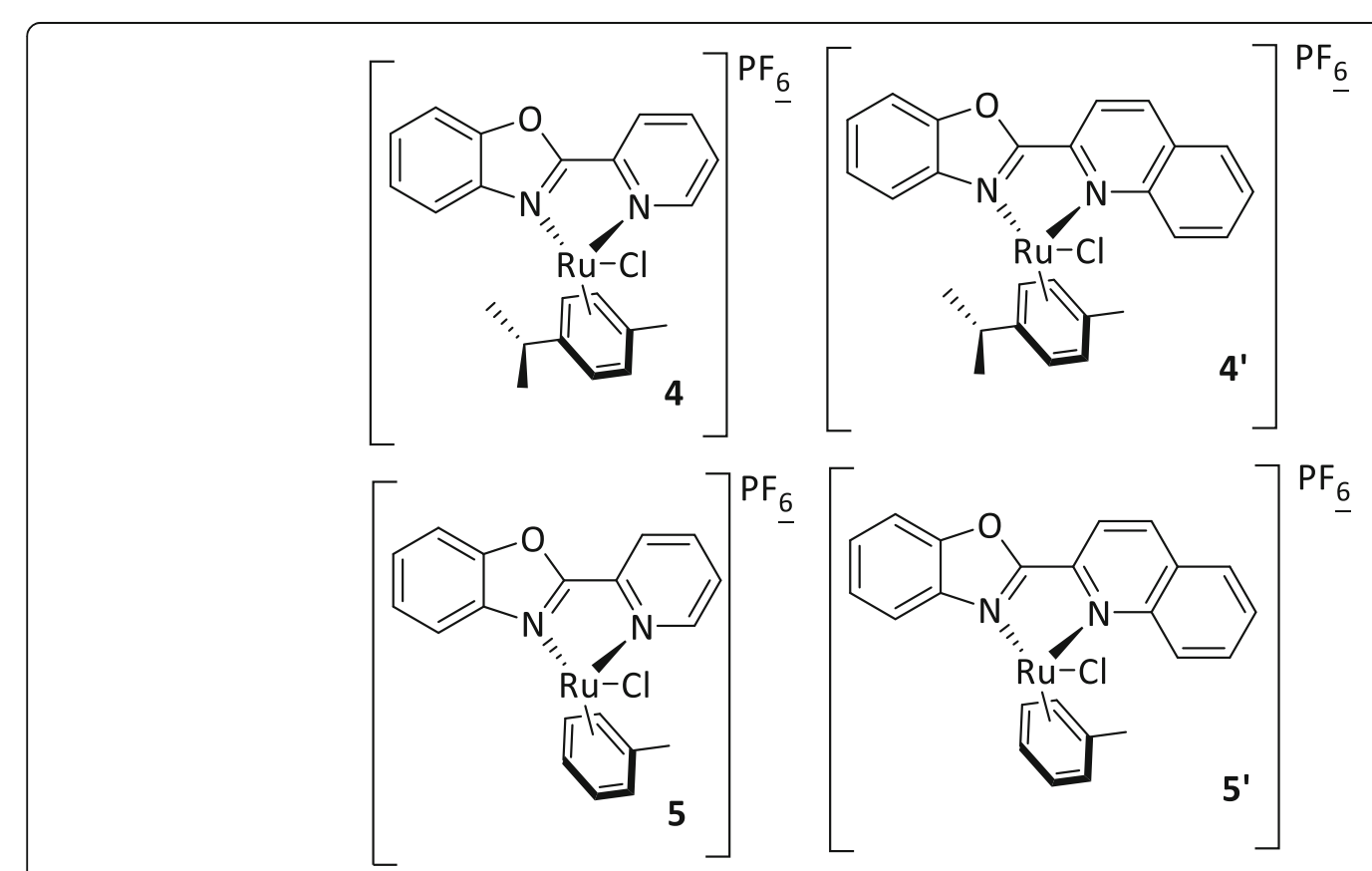

Fig. $42 \mathrm{Ru}(\mathrm{II})$-arene-2-pyridinylbenzoxazole complexes 


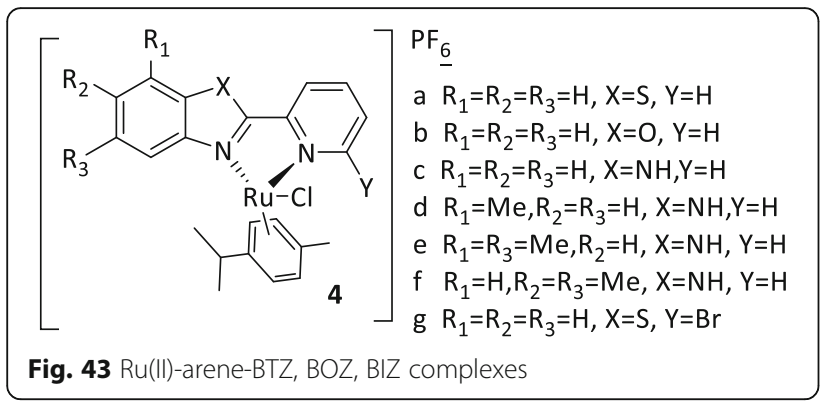

activity was tested. Multidrug resistance [74, 75] of cancer means the cancer cells become resistant to the various cytotoxic drugs. The cytotoxic activity of these ligands and complexes were measured through MTT assay, and it was observed that as compared to the free ligand the $\mathrm{Cu}(\mathrm{II})$ and $\mathrm{Zn}(\mathrm{II})$ complexes were more potent, and there was 29- and 5-fold increase in activity of $\mathrm{Cu}(\mathrm{II})$ and $\mathrm{Zn}$ (II) complexes as compared to free ligands. Verapamil was used as a positive control in this case.

The DNA has several binding site on which the small molecules are bonded through covalent and noncovalent bonds. The binding of $\mathrm{Ru}(\mathrm{II})$ complexes to DNA was reported to be the main factor in the anticancer effects of these complexes. Two $\mathrm{Ru}(\mathrm{II})$ complexes, NAMI-A and KP1019, are under advanced clinical evaluation as anticancer drugs [76]. A number of $\mathrm{Ru}(\mathrm{II})$ complexes bearing $\pi$-bonded arene ligands exhibit promising anticancer activities [77]. De and team [78] have prepared $4 \mathrm{Ru}(\mathrm{II})$-arene-2-pyridinylbenzoxazole complexes (Fig. 42) and characterized. MTT assay results indicate that all complexes exhibit highly selective cytotoxicity for two cancer cell lines (Caco-2 and HeLa) with respect to normal HEK-293 cells. Among the complexes, 4' and 5 show the highest cytoselectivities for the Caco-2 and HeLa cell lines, respectively.

Bioactive compounds are observed to exhibit improved biological activity upon coordination with transitional metal ions [79, 80]. Paira and team [81] have synthesized few $\mathrm{Ru}(\mathrm{II})$-arene complexes of benzimidazole, benzoxazole, and benzothiazole (Fig. 43) using Amberlite IR-120(H) as the catalyst. This method is environment friendly and gives a scope to prepare a series of ruthenium compounds for anticancer screening. All the compounds synthesized have shown great cytotoxicity activity against HeLa, MCF-7, and A2780 cell lines as compared to cisplatin standard drug. Compound $4 \mathrm{~g}$ was found to possess the most potent cytotoxic activity and selectivity in the cancer cell lines.

Two new mononuclear mixed ligand copper (II) complexes [82] (Fig. 44) were prepared, and their interaction with the DNA was investigated. Previously, copper(II) complexes are reported to show a variety of biochemical activity in different areas like anticancer [83]. The dipeptides utilized in these compounds are (Gly-gly and GlyL-leu) glycylglycine anion and glycyl-L-leucine anion respectively for compounds 1 and 2. Both these compounds were found to bind to calf thymus DNA through an intercalative mode. The anticancer activity of these two compounds were investigated against three cell lines HeLa (cervical), PC-3 (prostatic), and A549 (pulmonary). Cisplatin was used as a positive control. It was observed that compound 2 has more cytotoxic effect as compared to compound-1. These could be due to longer hydrocarbon chain associated with compound- 2 and making it more permeable in the cell membrane.

Similarly, 3 more $\mathrm{Cu}$ (II) dipeptide complexes (Fig. 45) $\left[\mathrm{Cu}(\mathrm{Gly}-\mathrm{L}-\mathrm{Val})(\mathrm{HPMB}) \mathrm{H}_{2} \mathrm{O}\right] \cdot \mathrm{ClO}_{4} \cdot \mathrm{H}_{2} \mathrm{O}$ (1), [Cu(Gly-L$\left.\mathrm{Val})(\mathrm{TBZ}) \mathrm{H}_{2} \mathrm{O}\right] \cdot \mathrm{ClO}_{4}$ (2), and [Cu(Gly-L-Val)(PBO)$\left.\mathrm{H}_{2} \mathrm{O}\right] \cdot \mathrm{ClO}_{4}$ (3) (Gly-L-Val = glycyl-L-valine anion, HPBM $=5$-methyl-2-(2'-pyridyl $)$ benzimidazole, TBZ = 2-(4'-thiazolyl) benzimidazole, $\mathrm{PBO}=2$-(2'-pyridyl) benzoxazole) were prepared [84], and their interaction with the DNA was studied using UV-visible, fluorescence, viscosity, thermal denaturation and docking study (PDB ID: 454D). The results showed that all these three compounds bind to DNA through an intercalative mode as like the previous compounds. The anticancer activity of these complexes were also studied against A549, PC-3, HeLa, and 3T3 cell lines with cisplatin as a standard,

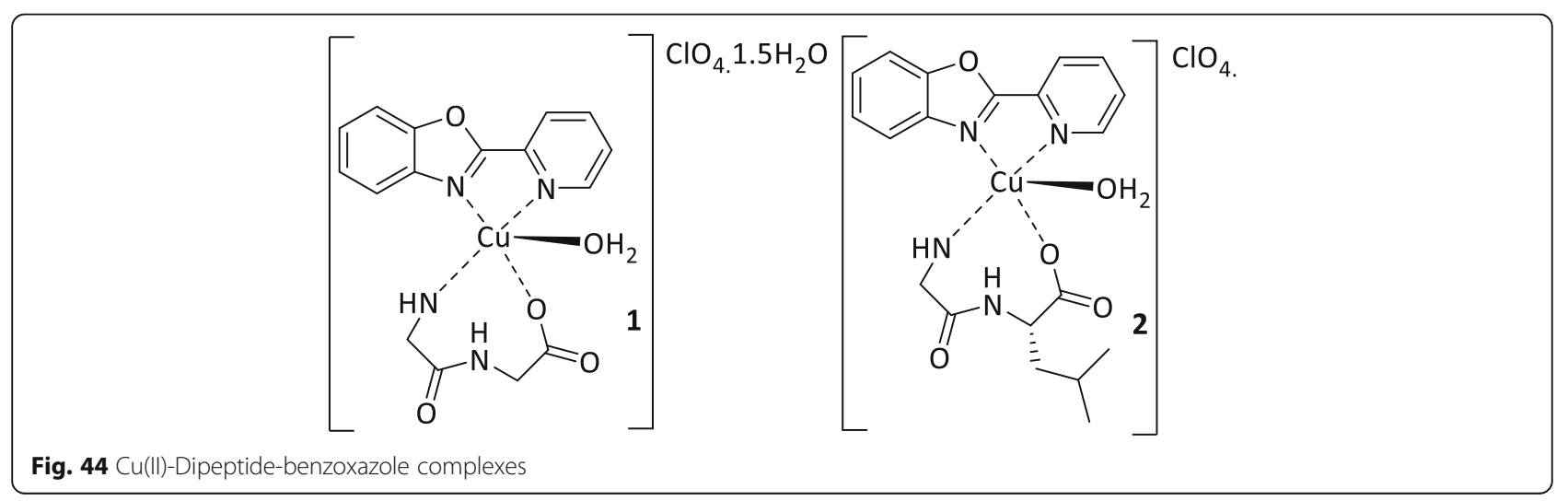




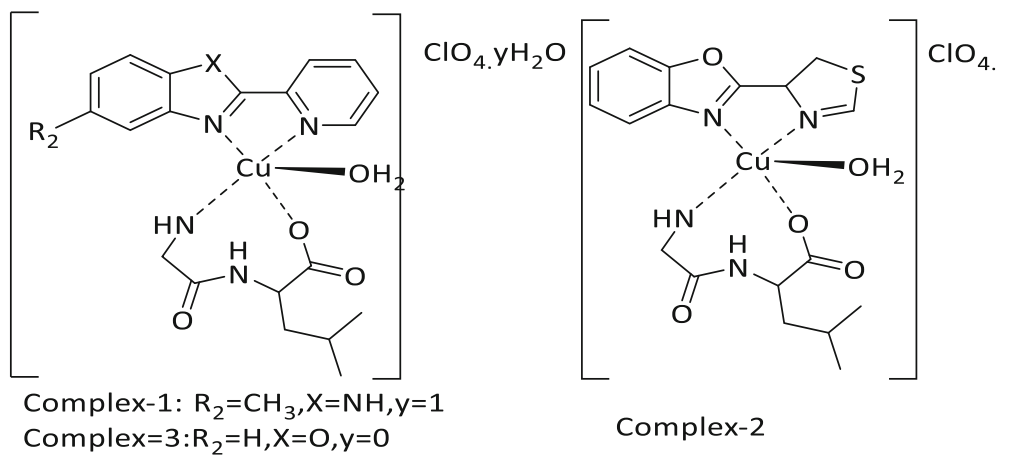

Fig. 45 Few more $\mathrm{Cu}(\mathrm{II})$-dipeptide-benzoxazole complexes

and the results suggested that compound 1 is more potent than compound- 2 which was more potent than compound-3.

\section{5-Hydroxybenzoxazole derivative}

Thymoquinone is a natural product which is reported to exhibit antitumor activity [85]. Amination at C3 of thymoquinone also improved the antitumor activity of ATQ (Fig. 46) A series of benzoxazole compounds were synthesized by using thymoquinone [86] (TQ/ARQ) as the starting material. These compounds were observed to have better cytotoxicity values as compared to TQ and ATQ when they were evaluated against 4 cancer cell lines (SW620, CFPAC-1, HepG2, and HeLa). Human lung fibroblast (WI38) was used as healthy control cell lines which help in finding the effect of these chemicals over healthy and normal cells. Compound if was observed to have potent activity against cancer cell lines while compound 1e was less toxic against the WI38 cell lines.

2-Aryl 5-hydroxy benzo[d]oxazoles [87] (Fig. 47) were synthesized in a one pot starting from orthodisubstituted precursor and amino phenols with toluene as a solvent and manganese dioxide as the oxidant. The series of these compounds were evaluated against 5 cancer cell lines as well as noncancerous cells and most of them showed good anticancer activity.

It was observed that the chlorine on the aryl at meta position (TDNSS-10) showed the best activity against the halogen substitution at the ortho-position of the aryl group.

\section{5-Aminobenzoxazole derivative}

AZD6244 (selumetinib) was discovered by Array BioPharma, and it is a highly selective MEK1 inhibitor [88], but it was having some limitations, so novel benzoxazole compound (KZ-001, Fig. 48) was developed which was prepared to overcome the limitations of AZD6244. KZ001 [89] was highly potent and was selective against selective MEK1 and 2 inhibitors. KZ-001 was observed to have 30 times greater inhibition BRAF and KRAS mutant tumor cells as compared to AZD6244. To determine its potential clinical application, the synergistic effect of KZ-001 with other agents was investigated both in vitro and in vivo (xenograft models). KZ-001 exhibited synergistic anticancer effect in combination with BRAF inhibitor vemurafenib and a microtubulestabilizing chemotherapeutic agent docetaxel.

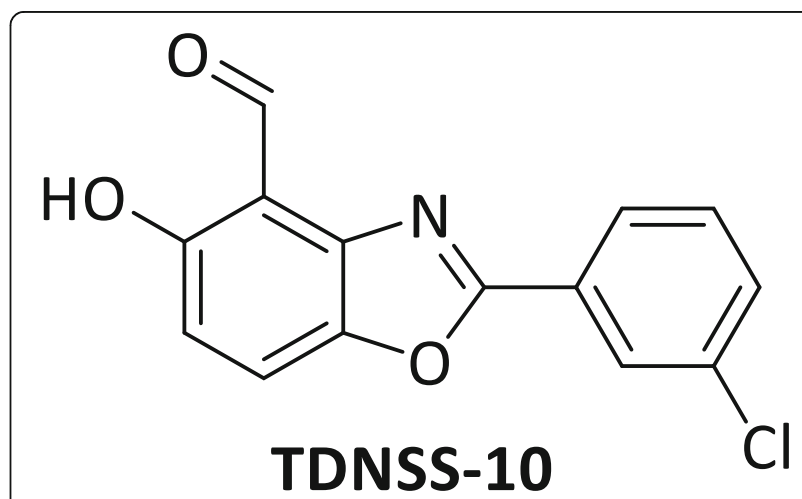

Fig. 47 2-Aryl 5-hydroxy benzo[d]oxazoles as anticancer
$1 \mathrm{f}=$ 4-F-Phenyl

$\operatorname{Ar}=1 \mathrm{a}=$ Phenyl $1 \mathrm{~g}=4-$ Nitro-Phenyl $1 \mathrm{c}=2-$ Naphthol $1 \mathrm{c}=4-$ Methoxy Phenyl

$\begin{array}{ll}1 \mathrm{~d}=4-\mathrm{Br}-\text { Phenyl } & 1 \mathrm{~d}=4-\mathrm{OH}-3-\text { OMe Phenyl } \\ 1 \mathrm{e}=4-\text { Ch-Phenyl } & 1 \mathrm{e}=2-\text { Thiophene }\end{array}$
Fig. 46 Thymoquinone derivatives

$\begin{array}{ll}1 \mathrm{~d}=4-\mathrm{Br}-\text { Phenyl } & 1 \mathrm{~d}=4-\mathrm{OH}-3-\mathrm{OMe} \\ 1 \mathrm{e}=4-\text { Ch-Phenyl } & 1 \mathrm{e}=2-\text { Thiophene }\end{array}$ 
<smiles>[R]OC(=O)O[Na]</smiles><smiles>Cn1cnc2c(F)c(Nc3ccc(Br)cc3Cl)c(C(=O)NOCCO)cc21</smiles>

Fig. 48 Benzoxazole compounds as MEK1 inhibitor

\section{2-Aminobenzoxazole derivative}

An and team [90] have developed a novel series of benzoxazole compounds (Fig. 49) which inhibit the Aurora kinase [91]. Aurora kinases are of 3 types A, B, and C, and all these kinases are associated with human cancer [92]. It was understood that regiochemistry, linker length, and halogen substitution plays an important role in the activity of these compounds. All the compounds were more effective in inhibiting the Aurora-B kinase, and molecular docking was done of these compounds to understand the selectivity of Autrora-A and B kinase. Further, compound 131 and $13 q$ have shown very good cytotoxicity activity. Compound $13 \mathrm{q}$ has shown very good activity against prostate cancer PC-3 tumor xenograft model.

\section{Benzoxazole-steroid derivative}

Abiraterone and galeterone are commonly used drugs for prostate cancer $[93,94]$. So eight noble oxazoline, benzoxazole, and benzimidazole compounds [95] (Fig. 50) were prepared from $3 \beta$-acetoxyandrosta-5,16-dien-17-carboxylic, $3 \beta$-acetoxyandrost-5-en-17 $\beta$-carboxylic, and $3 \beta$ acetoxypregn-5-en-21-oic acids. The molecular docking of these compounds (PDB code 3RUK) suggests that they form stable complexes with the enzyme. The new compounds (steroid moiety) are positioned in the similar fashion as that of abiraterone and galeterone. These compounds were able to inhibit growth of prostate carcinoma LNCaP and PC-3 cells in $96 \mathrm{~h}$ incubation, but compounds 4 and 6 were more potent than abiraterone and galeterone in LNCaP cell lines.

\section{Pyrrolobenzodiazepine-benzoxazole derivative}

The benzoxazole, benzimidazole, and benzothiazole backbone which is very common for anticancer compounds [96] was reported to prepare through ligand-free cobalt nanoparticles. These nanoparticles of cobalt oxide promoted cyclization cross-coupling reaction without the use of ligands or additives. These compounds synthesized were further docked (PDB ID: 1NFK) with estrogen receptors to investigate their antibreast cancer activity.

Pyrrolobenzodiazepine moieties were previously evaluated for anticancer activities [97]. So new hybrid compounds were synthesized by attaching benzothiazole and benzoxazole with pyrrolobenzodiazepine moiety 94 (Fig. 51) which was further attached through different alkane or alkylamide spacers. Anticancer activity of these compounds was evaluated against A375 cell lines. One of the compounds of the series compound-17d showed potent anticancer activity with significant DNA-binding ability, and apoptosis caused G0/G1 phase arrest at sub-micromolar concentrations. To confirm the DNA-binding capacity of these series of compounds, molecular docking of these compounds was done, and compound $17 \mathrm{~d}$ was checked for in vivo activity in human colon cancer HT29 xenograft mice.

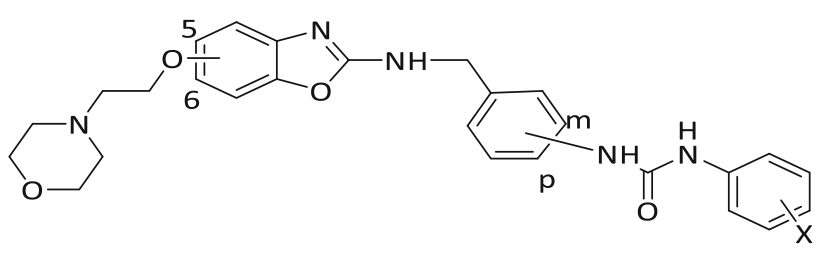




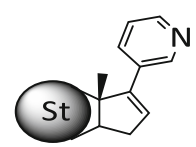

1 , abiraterone

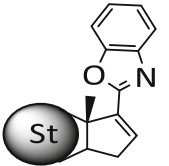

5

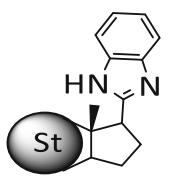

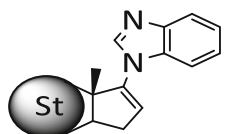

2 , galeterone

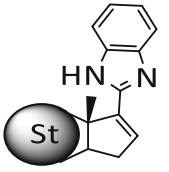

6

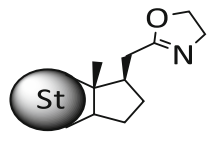

10

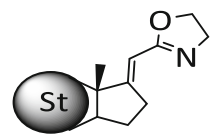

3

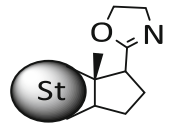

7

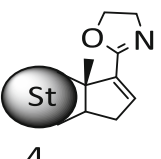

4

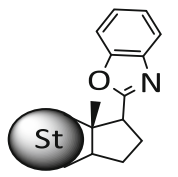

8

Fig. 50 Benzoxazole-steroid derivatives

\section{Conclusion}

Cancer possesses a continuous and series threat to the health of every individual in this world. Many researchers across the world are working on this direction to find a better treatment to this problem. Benzoxazole has been a very important moiety in drug discovery due to its diverse pharmacological activity. Present review explores the effect of various functionalization and substitution on benzoxazole and their effect on the anticancer activity. Various target areas like VEGF, VEGFR2, Topo-II, and MEK1 are discussed in the review as well. Further investigation in this direction may lead to development of new derivatives of benzoxazole with better activity, selectivity, and less toxic effect. These compiled data in the article will surely update the scientific community with the recent development in this area and will provide direction for further research in this area.<smiles>[R]c1cc(-c2[Z]c3ccccc3n2)ccc1Oc1ccc(Oc2cc3c(cc2OC)C(=O)N2CCC[C@H]2C=N3)c(OC)c1</smiles>

Fig. 51 Pyrrolobenzodiazepine-benzoxazole/benzothiazole compounds

\section{Abbreviations}

KF: Potassium fluoride; PBMC: Peripheral blood mononuclear cells; HepG2: Human hepatocellular carcinoma cell line; MCF-7: Human mammary carcinoma cell line; IC: Inhibitory concentration; Sp: Species; NMR: Nuclear magnetic resonance; AGS: American Geriatrics Society; Gl: Growth inhibitory; PPA: Polyphosphoric acid; S.I.: Système international; CA-4: Combretastatin-A4; COX-2: Cyclooxygenase-2; MTT: 3-(4,5-Dimethylthiazol-2-yl)-2,5diphenyltetrazolium bromide; ROESY: Rotating Frame Overhauser Effect Spectroscopy; DFQ-COSY: Double quantum-filtered correlation spectroscopy; HMBC: Heteronuclear multiple bond correlation spectroscopy; HMQC: Heteronuclear multiple quantum correlation spectroscopy; VEGF: Vascular endothelial growth factor; PDB: Protein Data Bank; DNA: Deoxyribonucleic acid; ACC: Acetyl-CoA carboxylase; Cu: Copper; Co: Cobalt; Ni: Nickel; Mg: Magnesium; Zn: Zinc; Ru: Ruthenium; MEK: Mitogen-activated protein kinase

\section{Acknowledgements}

We would like to thank Shri MM Patel College of Science and Research, Department of Chemistry, Kadi Sarvavishwavidlaya, for providing their intellectual, technical, and logistical support throughout the review work.

\section{Authors' contributions}

TG is the main author and he has collected, analyzed, conceived, and wrote the first draft. TP reviewed the draft and gave additional inputs to improve the scientific rigor required. Both authors read and approved the final draft for publication.

Funding

Not applicable

Availability of data and materials

Data and materials are available upon request.

Ethics approval and consent to participate

Not applicable

Consent for publication

Not applicable

Competing interests

There are no competing interests to declare for all authors. 
Received: 7 July 2020 Accepted: 15 September 2020 Published online: 21 November 2020

\section{References}

1. American Society of Clinical Oncology (2014) The state of cancer care in America, 2014: A report by the American Society of Clinical Oncology. J. Oncol. Pract. 10:119-142

2. Blackadar CB (2016) Historical review of the causes of cancer. World J Clin Oncol 7(1):54. https://doi.org/10.5306/wjco.v7.i1.54

3. Zajączkowska R, Kocot-Kępska M, Leppert W, Wrzosek A, Mika J, Wordliczek J (2019) Mechanisms of Chemotherapy-Induced Peripheral Neuropathy. Int J Molecular Sci 20(6):1451. https://doi.org/10.3390/ijms20061451

4. Hitchcock J, White AL, Hondow N, Hughes TA, Dupont H, Biggs S, Cayre OJ (2019) Metal-shell nanocapsules for the delivery of cancer drugs. J Colloid InterfaceScience. https://doi.org/10.1016/j.jcis.2019.12.018

5. Koga Y, Ochiai A (2019) Systematic Review of Patient-Derived Xenograft Models for Preclinical Studies of Anti-Cancer Drugs in Solid Tumors. Cells 8(5):418. https://doi.org/10.3390/cells8050418

6. Hanahan D, Weinberg RA (2011) Hallmarks of Cancer: The Next Generation. Cell 144(5):646-674. https://doi.org/10.1016/j.cell.2011.02.013

7. Rida S, Aashour F, Elhawash S, Elsemary M, Badr M, Shalaby M (2005) Synthesis of some novel benzoxazole derivatives as anticancer, anti-HIV-1 and antimicrobial agents. Euro J Med Chem 40(9):949-959. https://doi.org/ 10.1016/j.ejmech.2005.03.023

8. Kapileswar Seth, Sanjeev K. Garg, Raj Kumar, Priyank Purohit, Vachan S. Meena, Rohit Goyal, et al. Chakraborti 2-(2-Arylphenyl) benzoxazole As a Novel Anti-Inflammatory Scaffold: Synthesis and Biological Evaluation, Am Chem Soc Med. Chem. Lett., 2014; 5(5):512-516. doi:https://doi.org/10.1021/ ml400500e

9. Angajala G, Subashini R (2019) Synthesis, molecular modeling, and pharmacological evaluation of new 2-substituted benzoxazole derivatives as potent anti-inflammatory agents. Structural Chemistry. https://doi.org/10. 1007/s11224-019-01374-1

10. Anusha P, Rao J (2017) Venkateshwar; Mohan, G. KrishnaA review on diverse biological activities of benzoxazole molecule. World J Pharmacy Pharmaceutical Sciences 6(7):1779-1794. https://doi.org/10.20959/ wjpps20177-9608

11. Singh S, Veeraswamy G, Bhattarai D, Goo J-I, Lee K, Choi Y (2015) Recent Advances in the Development of Pharmacologically Active Compounds that Contain a Benzoxazole Scaffold. Asian Journal of Organic Chemistry 4(12):1338-1361. https://doi.org/10.1002/ajoc.201500235

12. Al-Harthy T, Zoghaib W, Pflüger M, Schöpel M, Önder K, Reitsammer M, Abdel-Jalil R (2016) Design, Synthesis, and Cytotoxicity of 5-Fluoro-2-methyl6-(4-aryl-piperazin-1-yl) Benzoxazoles. Molecules 21(10):1290. https://doi.org/ 10.3390/molecules21101290

13. Murty MSR, Ramalingeswara Rao B, Katiki MR, Nath LR, Anto RJ (2013) Synthesis of piperazinyl benzothiazole/benzoxazole derivatives coupled with 1,3,4-oxadiazole-2-thiol: novel hybrid heterocycles as anticancer agents. Medicinal Chemistry Research 22(10):4980-4991. https://doi.org/10.1007/ s00044-013-0510-y

14. Glomb T (2018) Karolina Szymankiewicz and Piotr Swiatek, Anti-Cancer Activity of Derivatives of 1,3,4-Oxadiazole. Molecules. Dec 23(12):3361. https://doi.org/10.3390/molecules23123361

15. Ravinaik B, Ramachandran D, Rao MVB (2019) Synthesis and Anticancer evaluation of Amide Derivatives of 1,3,4 -oxadiazole linked with Benzoxazole. Russian Journal of General Chemistry 89(5):1003-1008

16. Cascioferro S, Attanzio A, Di Sarno V, Musella S, Tesoriere L, Cirrincione G, Parrino B (2019) New 1,2,4-Oxadiazole Nortopsentin Derivatives with Cytotoxic Activity. Marine Drugs 17(1):35. https://doi.org/10.3390/ md17010035

17. Alexey Lukin, Ruben Karapetian, Yan Ivanenkov, Mikhail Krasavin, Privileged 1,2,4-Oxadiazoles in Anticancer Drug Design: Novel 5- Aryloxymethyl-1,2,4oxadiazole Leads for Prostate Cancer Therapy.(2019) Letters in Drug Design \& Discovery, Vol-13, Issue-3, 2016, 198-204. Doi: https://doi.org/10.2174/ 157018081299915081216425

18. Pervaram S, Ashok D, Sarasija M, Reddy CVR, Sridhar G (2018) Synthesis and Anticancer Activity of 1,2,4-Oxadiazole Fused Benzofuran Derivatives. Russ J Gen Chem 88(6):1219-1223. https://doi.org/10.1134/s1070363218060282

19. Abdelgawad MA, Bakr RB, Omar HA (2017) Design, synthesis and biological evaluation of some novel benzothiazole/benzoxazole and/or benzimidazole derivatives incorporating a pyrazole scaffold as antiproliferative agents. Bioorganic Chemistry 74:82-90. https://doi.org/10.1016/j.bioorg.2017.07.007

20. Srivastava A, Aggarwal L, Jain N (2014) One-Pot Sequential Alkynylation and Cycloaddition: Regioselective Construction and Biological Evaluation of Novel Benzoxazole-Triazole Derivatives. ACS Combinatorial Science 17(1): 39-48. https://doi.org/10.1021/co500135z

21. Kakkar, S., Kumar, S., Narasimhan, B., Lim, S. M., Ramasamy, K., Mani, V., \& Shah, S. A. A. (2018). Design, synthesis and biological potential of heterocyclic benzoxazole scaffolds as promising antimicrobial and anticancer agents. Chem Central J,2018, 12(1),96. doi: https://doi.org/10. 1186/s13065-018-0464-8.

22. Shreedhara, S. H.; Vagdevi, H. M.; Jayanna, N. D.; Raghavendra, R.; Kiranmayee, P.; Das, Prabhu; Mohammed, Shafeeulla. The in vitro Cytotoxic and Molecular Docking Studies of Newly Synthesized Fused BenzoxazoleTriazole Derivatives. R. J Chem Pharmaceutical Research (2017), 9(5), 108-119.

23. Dadashpour, Sakineh; Kucukkilinc, Tuba T.; Ercan, Ayse; Hosseinimehr, Seyed J.; Naderi, Nima; Irannejad, Hamid. Synthesis and Anticancer Activity of Benzimidazole/ Benzoxazole Substituted Triazolotriazines in Hepatocellular Carcinoma (2019). Anti-Cancer Agents in Medicinal Chemistry, 19(17), 21202129. doi:https://doi.org/10.2174/1871520619666190808152051

24. Bramhananda Reddy N, Burra VR, Ravindranath LK, Sreenivasulu R, Naresh Kumar V (2016) Synthesis and biological evaluation of benzoxazole fused combretastatin derivatives as anticancer agents. Monatshefte Für Chemie Chemical Monthly 147(3):593-598. https://doi.org/10.1007/s00706-016-1685-y

25. Kumar, Vukoti Kiran; Puli, Venkat Swamy; Babu, Ala Vasu; Ruddarraju, Radhakrishnam Raju; Prasad, K. R. S. Synthesis, anticancer evaluation, and molecular docking studies of benzoxazole linked combretastatin analogues (2020) Medicinal Chemistry Research, Ahead in print. doi: https://doi.org/10. 1007/s00044-020-02504-9

26. Sato S, Kajiura T, Noguchi M, Takehana K, Kobayashi T, Tsuji T (2001) AJI9561, a New Cytotoxic Benzoxazole Derivative Produced by Streptomyces sp. J Antibiotics 54(1):102-104. https://doi.org/10.7164/ antibiotics.54.102

27. Uuki M, Ueno K, Miyadohl S, Abe K, Shibata K, Taniguchi M, Oi S (1993) UK1, a novel cytotoxic metabolite from Streptomyces sp. 517-02. I. Taxonomy, fermentation, isolation, physico-chemical and biological properties. J Antibiotics 46(7):1089-1094. https://doi.org/10.7164/antibiotics.46.1089

28. Kumar D, Jacob MR, Reynolds MB, Kerwin SM (2002) Synthesis and evaluation of anticancer benzoxazoles and benzimidazoles related to UK-1. Bioorganic \& Medicinal Chemistry 10(12):3997-4004. https://doi.org/10.1016/ s0968-0896(02)00327-9

29. Huang S-T, Hsei J, Chen C (2006) Synthesis and anticancer evaluation of bis(benzimidazoles), bis(benzoxazoles), and benzothiazoles. Bioorganic \& Medicinal Chemistry 14(17):6106-6119. https://doi.org/10.1016/j.bmc.2006.05.007

30. McKee, M. L., \& Kerwin, S. M. (2008). Synthesis, metal ion binding, and biological evaluation of new anticancer 2-(2'-hydroxyphenyl)benzoxazole analogs of UK-1. Bioorganic \& Medicinal Chemistry, 16(4), 1775-1783.doi: https://doi.org/10.1016/j.bmc.2007.11.019

31. Sommer PSM, Almeida RC, Schneider K, Beil W, Süssmuth RD, Fiedler H-P (2008) Nataxazole, a New Benzoxazole Derivative with Antitumor Activity Produced by Streptomyces sp. Tü 6176. J. Antibiot. 61(11):683-686

32. Ayaz F, Kheeree R, Isse QA, Ersan RH, Algul O (2018) DNA Base Bioisosteres, Bis-benzoxazoles, Exert Anti-proliferative Effect on Human Prostate and Breast Cancer Cells. J Turkish Chem Soc, Section A: Chemistry 5(3):11451152. https://doi.org/10.18596/jotcsa.429504

33. Ayaz F, Ersan RH, Algul O (2019) Symmetric bis-benzoxazole-based chemicals exerted anti-inflammatory effect on danger signal LPS-stimulated macrophages. Monatshefte Für Chemie - Chemical Monthly. 2019(150): 1137-1146. https://doi.org/10.1007/s00706-019-02398-3

34. Sun M, Zhang X, Hao H, Li W, Lu C (2015) (2015). Nocarbenzoxazoles A-G, Benzoxazoles Produced by Halophilic Nocardiopsis lucentensis DSM 44048. J Natural Products 78(8):2123-2127. https://doi.org/10.1021/acs.jnatprod. 5 b00031

35. Kim T, Lee S-A, Noh T, Choi P, Choi S-J, Song BG, Ham J (2019) Synthesis, Structure Revision, and Cytotoxicity of Nocarbenzoxazole G. J Natural Products. 82(5):1325-1330. https://doi.org/10.1021/acs.jnatprod.9b00072

36. El-Hady HA (2014) Samar A. Abubshait, Synthesis and anticancer evaluation of imidazolinone and benzoxazole derivatives. Arab J Chem 10:S3725S3731. https://doi.org/10.1016/j.arabjc.2014.05.006

37. Abdelgawad MA, Belal A, Omar HA, Hegazy L, Rateb ME (2013) Synthesis, Anti-Breast Cancer Activity, and Molecular Modeling of Some Benzothiazole 
and Benzoxazole Derivatives. Archiv Der Pharmazie 346(7):534-541. https:// doi.org/10.1002/ardp.201300044

38. Belal A, Abdelgawad MA (2017) New benzothiazole/benzoxazole-pyrazole hybrids with potential as COX inhibitors: design, synthesis and anticancer activity evaluation. Research on Chemical Intermediates 43(7):3859-3872. https://doi.org/10.1007/s11164-016-2851-x

39. Rajyalakshmi G, Rama Narsimha Reddy A, Sarangapani M (2012) Synthesis and Biological Activities of Some Novel 2-Amino-(5 or 7-Substituted- 2Oxoindolin-3-Ylidene) Benzoxazole-5-Carbohydrazide Derivatives. Letters in Drug Design \& Discovery 9(6):625-632. https://doi.org/10.2174/ 157018012800673029

40. Altintop MD, Akalin Ciftci G, Temel HE (2018) Synthesis and evaluation of new benzoxazole derivatives as potential antiglioma agents. Marmara Pharm J 22(4):547-558. https://doi.org/10.12991/jrp.2018.97

41. Wang, Z; Shi, X.-H.; Wang, J.; Zhou, T.; Xu, Y.-Z.; Huang, T.-T.; Li, Y.-F.; Zhao, Y.-L.;Yang, L.; Yang, S.-Y.; et al. Synthesis, structure-activity relationships and preliminary antitumor evalutation of benzothiazole-2-thiol derivatives as novel apoptosis inducers. Bioorg. Med. Chem.Lett. 2011, 21, 1907-1101.doi: https://doi.org/10.1016/j.bmcl.2010.12.124.

42. Xiang P, Zhou T, Wang L, Sun C-Y, Hu J, Zhao Y-L, Yang L (2012) Novel Benzothiazole, Benzimidazole and Benzoxazole Derivatives as Potential Antitumor Agents: Synthesis and Preliminary in Vitro Biological Evaluation. Molecules 17(1):873-883. https://doi.org/10.3390/molecules17010873

43. Khodair Al, Al-Masoudi NA, Gesson J-P (2003) A New Approach to the Synthesis of Benzothiazole, Benzoxazole, and Pyridine Nucleosides as Potential Antitumor Agents. Nucleosides, Nucleotides and Nucleic Acids 22(11):2061-2076. https://doi.org/10.1081/ncn-120026407

44. Aiello S, Wells G, Stone EL, Kadri H, Bazzi R, Bell DR, Westwell AD (2008) Synthesis and Biological Properties of Benzothiazole, Benzoxazole, and Chromen-4-one Analogues of the Potent Antitumor Agent 2-(3,4Dimethoxyphenyl)-5-fluorobenzothiazole (PMX 610, NSC 721648)(1). J Med Chem 51(16):5135-5139. https://doi.org/10.1021/jm800418z

45. Thiriveedhi, Arunkumar; Nadh, Ratnakaram Venkata; Srinivasu, Navuluri; Ganta, Narayana Murthy, Novel Pyrazolyl Benzoxazole conjugates: Design, Synthesis, Molecular Docking and in vitro Anticancer activities (2019). Letters in Organic Chemistry, Volume16, Issue8, Pages619-626. doi: https://doi.org/ $10.2174 / 1570178615666181022141919$

46. Desai S, Desai V, Shingade S (2019) In-vitro Anti-cancer Assay and Apoptotic Cell Pathway of Newly Synthesized Benzoxazole-N-Heterocyclic Hybrids as Potent Tyrosine Kinase Inhibitors. Bioorganic Chemistry:103382. https://doi. org/10.1016/j.bioorg.2019.103382

47. Niu G, Chen X (2010) Curr. Vascular endothelial growth factor as an antiangiogenic target for cancer therapy. Drug Targets 11:1000. https://doi.org/ 10.2174/138945010791591395

48. Holmes K, Roberts OL, Thomas AM, Cross MJ (2007) Vascular endothelial growth factor receptor-2: Structure, function, intracellular signalling and therapeutic inhibition. Cellular Signalling 19(10):2003-2012. https://doi.org/ 10.1016/j.cellsig.2007.05.013

49. Wilhelm S, Carter C, Lynch M, Lowinger T, Dumas J, Smith RA, Schwartz B, Simantov R, Kelley $S$ Discovery and development of sorafenib: a multikinase inhibitor for treating cancer (2006). Nat. Rev. Drug Discov 5:835

50. Pircher A, Hilbe W, Heidegger I, Drevs J, Tichelli A, Medinger M (2011) Biomarkers in Tumor Angiogenesis and Anti-Angiogenic Therapy. International Journal of Molecular Sciences 12(10):7077-7099. https://doi. org/10.3390/ijms12107077

51. El-Helby, Abdel-Ghany A.; Sakr, Helmy; Eissa, Ibrahim H.; Al-Karmalawy, Ahmed A.: El-Adl, Khaled, Design, synthesis, molecular docking, and anticancer activity of benzoxazole derivatives as VEGFR-2 inhibitors (2019). Archiv der Pharmazie (Weinheim, Germany) , 352(12), 1900178. doi: https:// doi.org/10.1002/ardp.201900178

52. Yuan X, Yang Q, Liu T, Li K, Liu Y, Zhu C, Jin Y (2019) Design, synthesis and in vitro evaluation of 6-amide-2-aryl benzoxazole/benzimidazole derivatives against tumor cells by inhibiting VEGFR-2 kinase. Euro J Med Chem. https:// doi.org/10.1016/j.ejmech.2019.06.054

53. El-Helby, Abdel-Ghany A.; Sakr, Helmy; Eissa, Ibrahim H.; Al-Karmalawy, Ahmed A, Hamada Abulkhair, El-Adl, Khaled. Design, synthesis, molecular docking, and anticancer activity of benzoxazole derivatives as VEGFR-2 inhibitors (2019). Arch Pharm Chem Life Sci.ie1900113. doi: https://doi.org/ 10.1002/ardp.201900113

54. Ertan-Bolelli T, Musdal Y, Bolelli K, Yilmaz S, Aksoy Y, Yildiz I, Yalcin I (2014) Synthesis and Biological Evaluation of 2-Substituted-5-(4- nitrophenylsulfonamido)benzoxazoles as Human GST P1-1 Inhibitors, and Description of the Binding Site Features. ChemMedChem 9(5):984-992. https://doi.org/10.1002/cmdc.201400010

55. Oksuzoglu E, Ertan-Bolelli T, Can H, Tarhan M, Ozturk K, Yildiz I (2016) Antitumor activities on $\mathrm{HL}-60$ human leukemia cell line, molecular docking, and quantum-chemical calculations of some sulfonamide-benzoxazoles. Artificial Cells, Nanomedicine, and Biotechnology 45(7):1388-1396. https:// doi.org/10.1080/21691401.2016.1241796

56. Madhavilatha B, Fatima N, Sabitha G, Reddy BVS, Yadav JS, Bhattacharjee D, Jain $N$ (2017) Synthesis of 1,2,3-triazole and isoxazole-linked pyrazole hybrids and their cytotoxic activity. Medicinal Chemistry Research 26(8): 1753-1763

57. Petrova KT, Potewar TM, Correia-da-Silva P, Barros MT, Calhelha RC, Ciric A et al (2015) Antimicrobial and cytotoxic activities of 1,2,3-triazole-sucrose derivatives. Carbohydrate Research 417:66-71. https://doi.org/10.1016/j. carres.2015.09.003

58. Kachaeva, M. V., Hodyna, D. M., Obernikhina, N. V., Pilyo, S. G., Kovalenko, Y. S., Prokopenko, V. M. Brovarets, V. S. (2019). Dependence of the anticancer activity of 1,3-oxazole derivatives on the donor/acceptor nature of his substitues. J Heterocyclic Chem. 2019;1-13. doi: https://doi.org/10.1002/jhet.3711

59. Dadmal, T. L., Appalanaidu, killari, Kumbhare, R. M., Mondal, T., Ramaiah M., J. , \& bhadra, manika pal. (2018). Synthesis and biological evaluation of triazole and isoxazole tagged Benzothiazole/Benzoxazole derivatives as potent cytotoxic agents. New J. Chem., 2018, 42, 15546-15551. DOl:https://doi.org/ 10.1039/c8nj01249k.

60. Ravikumar P, Raolji GSB, Venkata Sastry K, Kalidasua S, Balaaraju T (2018) Design, Synthesis, and Anticancer Evaluation of Tetrazole-Fused Benzoxazole Derivatives as Tubulin Binding Agents. Russ J Gen Chem 88(10):2183-2189

61. Abdelgawad, M. A., Bakr, R. B., Ahmad, W., Al-Sanea, M. M., \& Elshemy, H. A. H. (2019). New pyrimidine-benzoxazole/benzimidazole hybrids: Synthesis, Antioxidant, Cytotoxic Activity, in vitro Cyclooxygenase and phospholipase A2-V Inhibition. Bioorganic Chemistry,92(2019) 103218. DOl:https://doi.org/ 10.1016/j.bioorg.2019.103218

62. Seenaiah D, Ramachandra Reddy P, Mallikarjuna Reddy G, Padmaja A, Padmavathi V, Siva Krishna N (2014) Synthesis, antimicrobial and cytotoxic activities of pyrimidinyl benzoxazole benzothiazole and benzimidazole. Euro J Med Chem 77:1-7. https://doi.org/10.1016/j.ejmech.2014.02.050

63. Da Costa PM, da Costa MP, Carvalho AA, Cavalcanti SMT, de Oliveira Cardoso MV, de Oliveira Filho GB, Ferreira PMP (2015) Improvement of in vivo anticancer and antiangiogenic potential of thalidomide derivatives. Chemico-Biological Interactions 239:174-183. https://doi.org/10.1016/j.cbi. 2015.06.037

64. Philoppes, J. N., \& Lamie, P. F. (2019). Design and synthesis of new benzoxazole/benzothiazole-phthalimide hybrids as antitumor-apoptotic agents. Bioorganic Chemistry, 2019, 89,102978. doi:https://doi.org/10.1016/j. bioorg.2019.102978

65. Tumiatti V, Milelli A, Minarini A, Micco M, Gasperi Campani A, Roncuzzi L et al (2009) Design, Synthesis, and Biological Evaluation of Substituted Naphthalene Imides and Diimides as Anticancer Agent. J Med Chem 52(23): 7873-7877. https://doi.org/10.1021/jm901131m

66. Sk UH, Prakasha Gowda AS, Crampsie MA, Yun JK, Spratt TE, Amin S, Sharma AK (2011) Development of novel naphthalimide derivatives and their evaluation as potential melanoma therapeutics. Euro J Med Chem 46(8): 3331-3338. https://doi.org/10.1016/j.ejmech.2011.04.058

67. Lu Y-T, Chen T-L, Chang K-S, Chang C-M, Wei T-Y, Liu J-W, Shih T-L (2017) Synthesis of novel C4-benzazole naphthalimide derivatives with potent antitumor properties against murine melanoma. Bioorganic \& Medicinal Chemistry 25(2):789-794. https://doi.org/10.1016/j.bmc.2016.11.057

68. Sissi C, Palumbo M (2003) The Quinolone Family: From Antibacterial to Anticancer Agents. Current Medicinal Chemistry-Anti-Cancer Agents 3(6): 439-450. https://doi.org/10.2174/1568011033482279

69. Abdelgawad MA, Lamie PF, Ahmed OM (2016) Synthesis of New Quinolone Derivatives Linked to Benzothiazole or Benzoxazole Moieties as Anticancer and Anti-Oxidant Agents. Medicinal Chemistry 6(10):410/1-410/6. https:// doi.org/10.4172/2161-0444.1000410

70. Tangellamudi, R., Asano, M., Sasaki, M., Satoh, Y., Yamamoto, Y., Sumi, H., \& Maezaki, H. (2019). The Identification and Pharmacological Evaluation of Potent, Selective and Orally Available ACC1 Inhibitor. Bioorganic \& Medicinal Chemistry Letters, 126749.doi:https://doi.org/10.1016/j.bmcl.2019.126749

71. Xing G-X, Tao J-Y, Wang X-Y, Li Z-Z, Fang X-Y, Guo Y-X, Bo F, Xu H-J (2019) Synthesis, crystal structures and biological studies of three new benzoxazole 
derivatives containing pyridyl moiety. Chinese Journal of Structural Chemistry 38(11):1902-1908. https://doi.org/10.14102/j.cnki.0254-5861.2011-2365

72. Jiang J, Tang X, Dou W, Zhang H, Liu W, Wang C, Zheng J (2010) Synthesis and characterization of the ligand based on benzoxazole and its transition metal complexes: DNA-binding and antitumor activity. Journal of Inorganic Biochemistry 104:583-559. https://doi.org/10.1016/j.jinorgbio.2010.01.011

73. Spengler G, Kincses A, Racz B, Vagra B, Watanbe G, Saijo R, Sekiya H, Tamai E, Maki J, Molnar J, Kawase M (2018) Benzoxazole-based Zn(II) and Cu(II) Complexes Overcome Multidrug-resistance in Cancer. ANTICANCER RESEAR CH 38:6181-6187. https://doi.org/10.21873/anticanres.12971

74. Robert J, Jarry C (2003) Multidrug resistance-reversal agents. J Med Chem 46:4805-4817. https://doi.org/10.1021/jm030183a

75. Colabufo NA, Berardi F, Cantore M, Contino M, Inglese C, Niso M, Perrone R (2010) Perspectives of P-glycoprotein-modulating agents in oncology and neurodegenerative diseases: pharmaceutical, biological, and diagnostic potentials. J Med Chem 53:1883-1897. https://doi.org/10.1021/jm900743C

76. Hartinger CG, Zorbas-Seifried S, Jakupec MA, Kynast B, Zorbas H, Keppler BK (2006) From bench to bedside--preclinical and early clinical development of the anticancer agent indazolium trans-[tetrachlorobis $(1 \mathrm{H}$ indazole)ruthenate(III)] (KP1019 or FFC14A). J. Inorg. Biochem. 100:891-978. https://doi.org/10.1016/j.jinorgbio.2006.02.013

77. Mangiapia G, Vitiello G, Irace C, Santamaria R, Colonna A, Angelico R, Radulescu A, DErrico G, Montesarchio D, Paduano L (2013) Anticancer Cationic Ruthenium Nanovectors: From Rational Molecular Design to Cellular Uptake and Bioactivity. Biomacromolecules 14:2549-2560. https:// doi.org/10.1021/bm400104b

78. De, S., Chaudhuri, S. R., Panda, A., Jadhav, G. R., Kumar, R. S., Manohar, P, Kumar, S. K. A. (2019). Synthesis, characterisation, molecular docking, biomolecular interaction and cytotoxicity studies of novel ruthenium(ii)arene-2-heteroarylbenzoxazole complexes. New J. Chem., 2019,43, 32913302. doi:https://doi.org/10.1039/c8nj04999h

79. Bratsos I, Mitri E, Ravalico F, Zangrando E, Gianferrara T, Bergamo A, Alessio E (2012) New half sandwich Ru(ii) coordination compounds for anticancer activity. Dalton Trans. 41:7358-7371. https://doi.org/10.1039/C2DT30654A

80. Malipeddi M, Lakhani C, Chhabra M, Paira P, Vidya R (2015) An efficient synthesis and in vitro antibacterial evaluation of ruthenium-quinolinol complexes. Bioorganic \& Medicinal Chemistry Letters 25(15):2892-2896. https://doi.org/10.1016/j.bmcl.2015.05.063

81. Kottukulam Subran S, Banerjee S, Mondal A, Paira P (2016) Amberlite IR120(H)-mediated "on water" synthesis of novel anticancer ruthenium(II)-pcymene 2 pyridinylbenzothiazole (BTZ), 2-pyridinylbenzoxazole (BOZ) \& 2pyridinylbenzimidazole (BIZ) scaffolds. New Journal of Chemistry 40(12): 10333-10343. https://doi.org/10.1039/C6NJ02049F

82. Gan Q, Qi Y, Xiong Y, Fu Y, Le X (2017) Two New Mononuclear Copper(II)Dipeptide Complexes of 2-(2'-Pyridyl)Benzoxazole: DNA Interaction, Antioxidation and in Vitro Cytotoxicity Studies. J Fluorescence 27(2):701714. https://doi.org/10.1007/s10895-016-1999-5

83. Pulimamidi RR, Ravula C, Battu S (2016) New bio-based Cu(II) complexes and study of their anti-cancer activities. J Fluoresc 26:1183-1197. https://doi. org/10.1007/s10895-016-1801-8

84. Qi Y-Y, Liu Y-X, Gan Q, Xiong Y-H, Mao Z-W, Le X-Y (2018) Three new mixed-ligand copper(II) complexes containing glycyl-L-valine and N,Naromatic heterocyclic compounds: Synthesis, characterization, DNA interaction, cytotoxicity and antimicrobial activity. Applied Organometallic Chemistry 32(3). https://doi.org/10.1002/aoc.4126

85. Schneider-Stock R, Fakhoury IH, Zaki AM, El-Baba CO, Gali-Muhtasib HU (2014) Thymoquinone:Fifty years of success in the battle against cancer models. Drug Discov. Today. 19:18-30. https://doi.org/10.1016/j.drudis.2013. 08.021

86. Glamoclija, Una, Padhye, Subhash, Spirtovic-Halilovic, Selma, Osmanovic, Amar, Veljovic, Elma, Roca, Suncica, Novakovic, Irena, Mandic, Boris, Turel, Iztok, Kljun, Jakob; et al (2018). Synthesis, Biological Evaluation and Docking Studie of Benzoxazoles Derived from Thymoquinone. Molecules, 23(12), 3297/1-3297/17. DOl:https://doi.org/10.3390/molecules23123297

87. Tangellamudi, N. D., Shinde, S. B., Pooladanda, V., Godugu, C., \& Balasubramanian, S. (2018). Facile Synthesis of 2-aryl 5-Hydroxy Benzo[d]oxazoles and their in vitro anti-proliferative effects on various cancer cell lines. Bioorganic \& Medicinal Chemistry Letters. (2018), 28(23-24), 3639-3647 doi:https://doi.org/10.1016/j.bmcl.2018.10.038

88. Yeh TC, Marsh V, Bernat BA, Ballard J, Colwell H, Evans RJ, Wallace E (2007) Biological Characterization of ARRY-142886 (AZD6244), a Potent, Highly
Selective Mitogen-Activated Protein Kinase Kinase 1/2 Inhibitor. Clinical Cancer Research 13(5):1576-1583. https://doi.org/10.1158/1078-0432.CCR-061150

89. Cheng $Y$, Wang $X$, Xia X, Zhang W, Tian H (2019) A Benzoxazole compound as a novel MEK inhibitor for the treatment of RAS/RAF mutant cancer. Int J Cancer(2019) 145(2):586-596. https://doi.org/10.1002/ijc.32119

90. An Y, Lee E, Yu Y, Yun J, Lee MY, Kang JS, Kim W-Y, Jeon R (2016) Design and synthesis of novel benzoxazole analogs as Aurora B kinase inhibitors. Bioorganic \& Medicinal Chemistry Letters 26(13):3067-3072. https://doi.org/ 10.1016/j.bmcl.2016.05.017

91. Fu J, Bian M, Jiang Q, Zhang C (2007) Roles of Aurora Kinases in Mitosis and Tumorigenesis. Molecular Cancer Research 5(1):1-10. https://doi.org/10. 1158/1541-7786.MCR-06-0208

92. Hajipour AR, Khorsandi Z, Mortazavi M, Farrokhpour H (2015) Green, efficient and large-scale synthesis of benzimidazole, benzoxazole and benzothiazole derivatives using ligand-free cobalt-nanoparticles as potential anti-estrogen breast cancer agents, and study of their interactions with estrogen receptor by molecular docking. RSC Advances 5(130):107822-107828. https://doi.org/ 10.1039/C5RA22207A

93. Bhatnagar A, McKay MJ, Crumbaker M, Ahire K, Karuso P, Gurney H, Molloy MP (2018) Quantitation of the anticancer drug abiraterone and its metabolite $\Delta(4)$-abiraterone in human plasma using high-resolution mass spectrometry. J Pharmaceutical Biomedical Analysis 154:66-74. https://doi. org/10.1016/j.jpba.2018.03.012

94. Urszala, L M., Mahsa, A., Daniel, D., Namdev, N.Nay C.T.H.Chit, Robson, C. (2018). The novel anti-androgen candidate galeterone targets deubiquitinating enzymes, USP12 and USP46, to control prostate cancer growth and survival. Oncotarget, 9(38), 24992-25007. doi: https://doi.org/10. 18632/oncotarget.25167

95. Latysheva, A. S., Zolottsev, V. A., Veselovsky, A. V., Scherbakov, K. A., Morozevich, G. E., Pokrovsky, V. S.,Misharin, A. Y. (2019). New Steroidal Oxazolines, Benzoxazoles and Benzimidazoles Related to Abiraterone and Galeterone. Steroids,153,(2020),108534. doi:https://doi.org/10.1016/j.steroids. 2019.108534

96. Kamal A, Shetti RVCRNC, Ramaiah MJ, Swapna P, Reddy KS, Mallareddy A, Pal-Bhadra M ea (2011) Carbazole-pyrrolo[2,1-c][1,4]benzodiazepine conjugates: design, synthesis, and biological evaluation. Med Chem Comm 2(8):780. https://doi.org/10.1039/C1MD00072A

97. Ahmed Kamal, K. Srinivasa Reddy, M. Naseer A. Khan, Rajesh V. C. R. N. C. Shetti ,M. Janaki Ramaiah, S. N. C. V. L. Pushpavalli , Chatla Srinivas, Manika Pal-Bhadra, Mukesh Chourasia G. Narahari Sastry, Aarti Juvekar, Surekha Zingde, Madan Barkume. (2010). Synthesis, DNA-binding ability and anticancer activity of benzothiazole/benzoxazole-pyrrolo[2,1c][1,4]benzodiazepine conjugates. Bioorganic \& Medicinal Chemistry 18 4747-4761. doi: https://doi.org/10.1016/j.bmc.2010.05.007

\section{Publisher's Note}

Springer Nature remains neutral with regard to jurisdictional claims in published maps and institutional affiliations.

\section{Submit your manuscript to a SpringerOpen ${ }^{\circ}$ journal and benefit from:}

- Convenient online submission

- Rigorous peer review

- Open access: articles freely available online

- High visibility within the field

- Retaining the copyright to your article

Submit your next manuscript at $>$ springeropen.com 